\title{
La Enfermedad de Parkinson: Etiología, Tratamientos y Factores Preventivos
}

\section{Parkinson Disease: Etiology, Treatments and Preventive Factors}

DOI: $10.11144 / J a v e r i a n a . u p s y 15-5 . e p e t$

Recepción: 25 Agosto 2016 | Aprobación: 28 Noviembre 2016

\author{
F. Hurtado \\ Universidad de los Andes, Colombia \\ Melissa Andrea N Cardenas \\ Universidad de los Andes, Colombia \\ FERnando Cardenas \\ Universidad de los Andes, Colombia \\ Laura Andrea León \\ Universidad Sergio Arboleda, Colombia
}

Para citar este artículo: Hurtado, F., Cardenas, M. A. N., Cardenas, F. P., \& León, L. A. (2016). La Enfermedad de Parkinson: Etiología, Tratamientos y Factores Preventivos. Universitas Psychologica, 15(5). http://dx.doi.org/10.11144/Javeriana.upsy15-5.epet

\section{RESUMEN}

La enfermedad de Parkinson (EP) es la patología neurodegenerativa motora con mayor incidencia a nivel mundial, cuyas causas aún no son claras. Actualmente no existe cura, pero es posible contar con diferentes tratamientos que permiten aliviar algunos de sus síntomas y enlentecer su curso. Debido a la gran cantidad de informaciones, en ocasiones contradictorias sobre los llamados "factores de riesgo" (entendidos éstos como situaciones que pueden exacerbar la posibilidad de aparición de la enfermedad, incluyendo desde la predisposición familiar hasta la exposición prolongada a substancias exógenas), en esta revisión se pretende ofrecer una panorámica actual sobre factores asociados a la aparición de EP. Se revisan también algunos tratamientos que buscan contrarrestar la pérdida de la función dopaminérgica de la substancia nigra (SN) y algunas de las aproximaciones terapéuticas tanto farmacológicas, como por estimulación cerebral profunda (ECP) o por implante celular. Se revisan también investigaciones sobre el potencial terapéutico de compuestos con alta especificidad a receptores colinérgicos (nAChRs) y antagonistas de receptores de adenosina, específicamente del subtipo A2A. Posiblemente durante las próximas décadas, nuestro conocimiento en epigenética pueda arrojar nuevas luces sobre esta interacción, así como sobre las relaciones entre ciertas líneas de microbios intestinales y aparición de EP. En este momento, la alternativa terapéutica que ofrece mayor eficacia es la ECP, sin embargo, a futuro se espera que el desarrollo de nuevas estrategias de implante cerebral pueda ofrecer una cura real de la EP.

Palabras clave

Enfermedad de Parkinson (EP); estimulación cerebral profunda (ECP); sustancia nigra (SN); núcleo subtálamico (NST); globo pálido interno (GPi).

\begin{abstract}
Parkinson's disease (PD) is the most prevalent neurodegenerative motor pathology worldwide, the causes of which are still unclear. Currently there is no cure, but it is possible to have different treatments that allow to alleviate some of its symptoms and slow its course. Due to the large amount of information, sometimes contradictory, about the
\end{abstract}


so-called "risk factors" (understood as situations that may exacerbate the possibility of the onset of the disease, from family predisposition to prolonged exposure to exogenous substances), in this review aims to provide a current overview of factors associated with the occurrence of PD. We also review some treatments that seek to counteract the loss of the dopaminergic function of the substance nigra $(\mathrm{SN})$ and some of the therapeutic approaches both pharmacologically, by deep brain stimulation (DBS) or by cellular implantation. Also reviewed investigations on the therapeutic potential of compounds with high specificity to cholinergic receptors (nAChRs) and adenosine receptor antagonists, specifically the A2A subtype. Possibly, during the next decades, our knowledge in epigenetics may shed new light on this interaction, as well as on the relationships between certain lines of intestinal microbes and onset of PD. At this time, the most effective therapeutic alternative is DBS; however, in the future it is expected that the development of new brain implant strategies may offer a real cure for PD.

Keywords

Parkinson Disease (PD); Deep brain stimulation (DBS); substancia nigra (SN); subthalami nucleus (NST); globo pálido interno (GPi).

\section{Introducción}

La enfermedad de Parkinson (EP) es la segunda enfermedad neurodegenerativa con mayor prevalencia en el mundo después de la enfermedad de Alzheimer (Willis, 2013; Schapira, 2013). Se caracteriza por ser una enfermedad de curso lento manifestada por lo general alrededor de los 60 años de edad (Mayeux, 2003), existiendo también casos de inicio, anterior a los 50 años. Incluso existen reportes de casos de extrema peculiaridad, de inicio muy temprano, cuya aparición tiene inicio alrededor de los 20 años. Los signos cardinales de EP son aquinesia (ausencia sustancial de movimientos), temblor en estado de reposo, rigidez, aumento de la tensión muscular y resistencia al movimiento (rigidez en "dientes de sierra") e inestabilidad de la postura por pérdida del equilibrio, que lleva a frecuentes caídas y algunos otros síntomas que incluyen disartria y bradicinesia (Bartels \& Leenders, 2009; Pagano, Ferrara, Brooks, \& Pavese, 2016).

Esta revisión se propone exponer algunos de los datos más relevantes frente a la etiología, tratamientos principales y factores de prevención frente a esta enfermedad.

\section{Consideraciones etiológicas}

Los síntomas de EP pueden ser explicados por la prominente perdida de neuronas dopaminérgicas en la sustancia nigra (SN) (Tanner, 1989). Esta pérdida es causada, probablemente, por la sobreexpresión de proteínas tales como la \#sinucleína y por su mal plegamiento, lo que genera en ultimas una malformación estructural (Chen, Xie, Turkson, \& Zhuang, 2015). Esta anormalidad lleva a la disfunción de la cadena respiratoria neuronal y a la formación de cuerpos de Lewy (Lansbury, Jr. \& Brice, 2002). Diferentes estudios han mostrado que la formación de los cuerpos de Lewy se debe a un proceso de mal funcionamiento iniciado por la \#sinucleína que induce polimerización de la proteína TAU, llevando a su hiperfosforilación, la \#-sinucleína hiperfosforilada se presenta hasta en un $90 \%$ en casos de Parkinson y sólo en un 4\% en casos normales (Waxman \& Giasson, 2011). El aumento de proteína TAU hiperfosforilada lleva a la interrupción del proceso de formación de microtubulos, lo que causa aberraciones estructurales y funcionales de la neurona (Haggerty et al., 2011).

Algunos factores genéticos y ambientales han sido relacionados con la etiología de la enfermedad. Sin embargo, en la mayoría de los casos reportados (95\%) las causas son de tipo desconocido (Mizuno et al., 2001). Diversos estudios genéticos han permitido asociar ciertos genes específicos con la vulnerabilidad a desarrollar esta enfermedad. No obstante, es difícil determinar cuáles son los factores ambientales causantes del desarrollo de la patología.

\section{Factores Ambientales}

Los primeros síntomas de EP son evidentes tras la depleción dopaminérgica de aproximadamente el 80\% (Tanner, 1989; Shoulson et al., 2002). Esto sugiere una gran neurodegeneración antes de que los primeros síntomas de la enfermedad se hagan presentes. Por lo general esta neurodegeneración inicia varios años antes de ser sintomática, 
siendo entonces muy difícil discriminar con exactitud las causas. En estas circunstancias no es posible establecer las causas por las cuales un determinado paciente desarrolla la patología, ya que a lo largo de su vida pudo haber sido expuesto a muchos agentes tóxicos, o inclusive, a la interacción entre ellos, además de ser posible que presente una predisposición genética que le haya conferido cierta vulnerabilidad neuronal a la neurodegeneración dopaminérgica (Kumar, Djarmati-Westenberger, \& Grunewald, 2011; Laing, 2001; McGuire et al., 2011).

Se ha reportado una alta prevalencia de casos en países industrializados, entre sujetos que trabajan o han trabajado en cultivo de vegetales con pesticidas (por ejemplo, paraquat y rotenona) e industrias metaleras con alta exposición a cobre y a plomo (Gorell, Peterson, Rybicki, \& Johnson, 2004; Liou et al., 1997; Carpenter, 2001; Chwiej et al., 2008; Dexter et al., 1989; Gorell, Rybicki, Cole, \& Peterson, 1999; Kumudini et al., 2014; Willis et al., 2010; Yokel, 2006). Estudios de cohorte retrospectivos han logrado correlacionar la exposición a pesticidas con un 8.1\% de probabilidad de presentar la enfermedad, mientras que exposición al plomo y al cobre confiere un $3.9 \%$ de probabilidad (Gorell et al., 2004). Por ejemplo, en Taiwán donde paraquat es usado ampliamente en cultivos de arroz, se encontró una consistente correlación entre exposición y EP, mostrando que personas expuestas al pesticida, por más de 20 años tienen 6 veces mayor probabilidad de presentar la enfermedad (Liou et al., 1997). También se ha demostrado que exposiciones a otros pesticidas por periodos superiores a 30 años triplica la probabilidad de desarrollar la enfermedad (Bashkatova, Alam, Vanin, \& Schmidt, 2004; Betarbet et al., 2000; Drolet, Cannon, Montero, \& Greenamyre, 2009).

El primer incidente que permitió correlacionar claramente la exposición a factores exógenos con neurotoxicidad en el sistema nigroestriatal, sucedió a comienzos de los años 80 cuando un grupo de jóvenes se inyectaron intravenosamente 1-methyl-4-phenyl-1,2,3,6tetrahydropyridine (MPTP), subproducto de la 1-methyl-4-phenyl-4-propionoxipiperidina (MPPP), análogo a la meperidina y con efectos parecidos a la heroína. Los sujetos pronto desarrollaron alteraciones motrices de tipo parkinsoniano similares a las presentes en sujetos parkinsónicos (Langston, Langston, \& Irwin, 1984). Esto sugirió la existencia de sustancias toxicas ambientales causales de EP idiopática.

Hoy en día MPTP, 6-hidroxidopamina (6OHDA), rotenona y paraquat son algunas de las sustancias usadas en laboratorios para modelar la enfermedad de Parkinson.

Cuando la MPTP llega al cerebro, ésta es metabolizada a 1-methyl-4-phenylpyridinium $(\mathrm{MPP}+)$ por la monoaminooxidasa-B (MAOB) glial, luego el MPP+ es selectivamente transportado por el transportador de dopamina (DAT) hacia el interior de las neuronas dopaminérgicas donde causa daño al complejo mitocondrial I, que lleva a la pérdida de la actividad mitocondrial, con la consecuente disminución de producción y uso de ATP (Reznikoff, Manaker, Parsons, Rhodes, \& Rainbow, 1985; Glover, Gibb, \& Sandler, 1986) y a un incremento en la producción de especies reactivas de oxigeno (ROS) (Singer, Castagnoli, Jr., Ramsay, \& Trevor, 1987; Singer \& Ramsay, 1990). Este proceso implica la muerte celular. El mismo mecanismo de acción es el responsable de los efectos tóxicos de la 6-OHDA, cuyo ingreso al ambiente intraneuronal también se da por los transportadores de membrana.

Algunos otros estudios post-mortem han encontrado residuos de pesticidas en los cerebros de pacientes con Parkinson y Alzheimer al igual que elevados niveles de mediadores proinflamatorios como TNF\#, IL-1\#, óxido nítrico y aumento en la producción de ROS en la sustancia nigra (Naoi, Maruyama, Niwa, \& Nagatsu, 1994; Nagatsu, Mogi, Ichinose, \& Togari, 2000; Nagatsu, Mogi, Ichinose, \& Togari, 2000; Varani et al., 2010; McCoy, Ruhn, Blesch, \& Tansey, 2011; Zhang et al., 2012; Tong et al., 2016). Por todas estas razones se ha sugerido que exposición a toxinas junto con procesos inflamatorios mediados por microglía, deben mediar el desarrollo y aparición de EP. Se sabe también, que la pérdida dopaminérgica asociada 
a estas sustancias no se da necesariamente tras una única exposición, sino que, por el contrario, es necesaria la constante exposición a estos agentes. Por ejemplo, Bretaud y colaboradores (2004) encontraron que a diferencia de los efectos neurotóxicos inducidos por MPTP que pueden ser alcanzados tras una única exposición, dependiendo de la especie, edad y vía de administración de la misma - los efectos de paraquat y rotenona son alcanzados sólo tras altas dosis y largas exposiciones a las dos sustancias, pues la exposición a sólo una, no parece inducir EP. Sin embargo, estos efectos dependen también de la especie. Se ha reportado, por ejemplo, que en ratas Sprague Dawley, la exposición a dosis altas de rotenona por cortos periodos de tiempo, genera alteraciones cardiovasculares, pero no lesiones específicas en el cerebro (Sherer et al., 2002; Betarbet et al., 2000). La depleción dopaminérgica en el sistema nigroestriatal es proporcional al tiempo de exposición. En el estudio de Betarbet y colaboradores también se demostró que las terminales nerviosas del estriado son las primeras en presentar denervación dopaminérgica.

Se ha demostrado que cortos períodos de exposición independiente a rotenona o a un agente inflamatorio lipopolisacárido, no generan daños significativos en neuronas dopaminérgicas in-vitro, mientras que la exposición simultánea a bajas cantidades de las dos substancias llevaba a una reducción del $60 \%$ en la captación de dopamina, $48 \%$ en la pérdida de tirosina hidroxilasa $(\mathrm{TH})$ y un recogimiento del 60\% en la longitud de las dendritas (Gao, Hong, Zhang, \& Liu, 2003). Resultados similares fueron encontrados en modelos con ratas por (Zhou et al., 2012). Estos hallazgos confirman la hipótesis de que la neurodegeneración dopaminérgica en el estriado debe estar mediada por la sinergia entre estados de inflamación y agentes tóxicos provenientes del ambiente.

En cualquier caso, resulta intrigante por qué las neuronas dopaminérgicas de la pars compacta de la substancia nigra (SNc) son mucho más vulnerables a sufrir daño por toxinas que neuronas dopaminérgicas en otras regiones encefálicas. Una posible explicación radica en la morfología misma de las neuronas en cada región. Pacelli y colaboradores (Pacelli et al., 2015), encontraron que neuronas dopaminérgicas en la SNc presentan una mayor arborización axonal y densidad mitocondrial en el axón que neuronas dopaminérgicas de otras regiones. Por consiguiente, parece que las neuronas dopaminérgicas en SNc tienen una demanda energética mayor y menores reservas de energía; lo que conlleva a un elevado y crónico estado de estrés oxidativo lo que consecuentemente podría aumentarles la vulnerabilidad a eventos tóxicos ambientales y/o propios del envejecimiento.

Algunos otros factores ambientales, tales como la exposición a metales pesados, no están tan altamente correlacionados - como los pesticidas - en la aparición de EP. Existen reportes que señalan la exposición a metales como un factor generador de estados de inflamación que, en coexistencia o sinérgica con herbicidas y/o pesticidas, incrementan abruptamente el riesgo de desarrollar la enfermedad (Willis et al., 2010).

Estudios in-vitro han demostrado que la exposición a ciertos metales podría inducir cambios en la conformación de la \#-sinucleína acelerando su fosforilación (Braithwaite, Stock, $\&$ Mouradian, 2012; Yin et al., 2014). Algunos estudios han encontrado que la prolongada exposición a metales pesados está asociada al desarrollo de la enfermedad de Parkinson, estas correlaciones han sido validadas en modelos animales y en estudios in-vitro (Jinsmaa et al., 2014; Kumudini et al., 2014; Rubio-Osornio et al., 2013; Meloni \& Vasak, 2011; Lu, Prudent, Fauvet, Lashuel, \& Girault, 2011). Todos los hallazgos apuntan a que la muerte neuronal dopaminérgica en el sistema nigroestriatal es producida por exposición continua durante años a agentes tóxicos y no sólo por la exposición a un único agente en ocasiones esporádicas. Sin embargo, estos estudios epidemiológicos no están libres de sesgos, ya que sus metodologías de correlación residen en los reportes de los pacientes acerca de exposiciones y estilos de vida en décadas anteriores. El estudio realizado por Semchuk y colaboradores (1991), por ejemplo, mostró que sólo en $10 \%$ de los casos existía una correlación consistente entre la exposición 
a herbicidas por varias décadas y el desarrollo de EP. El 90\% restante se debería a factores aún desconocidos. Finalmente, es importante mencionar que los efectos de la exposición a pesticidas o metales pesados pueden variar de acuerdo a las diferencias genéticas de cada individuo, por lo cual el análisis genético en estudios epidemiológicos y de correlación podría ayudar a esclarecer mucho mejor la verdadera etiología de la enfermedad.

\section{Epigenética}

La forma en la que el ambiente interactúa con la conformación genética particular aún no es clara, pero es posible que estén implicados factores epigenéticos. Algunos genes no son expresables (o su expresión silenciada) a menos que interactúen con el ambiente y reciban una señal particular. Algunos estudios han mostrado que el gen para la \#-sinucleina tiene una regulación epigenética (Jowaed, Schmitt, Kaut, \& Wullner, 2010). Específicamente estudios con pacientes diagnosticados con EP mostraron que hay una ausencia de la regulación de la acetilación de histonas para este gen, mientras que la metilación del DNA se mantiene intacta, aumentando la expresión del gen en áreas como la substancia nigra, el putamen y la corteza (Coppede et al., 2016). La \#-sinucleina genera un decremento en la acetilación (desacetilación) de la histona 3, de esta forma se generan cambios transcripcionales que pueden llevar a muerte celular (Kontopoulos, Parvin, \& Feany, 2006). Inhibidores de la desacetilación de la histona 3 producen un efecto neuroprotector en células dopaminérgicas ante la administración de 6OHDA y MPTP (Zhou et al., 2011). Otros estudios han mostrado que la \#-sinucleina tiene propiedades epigeneticas por sí misma, como por ejemplo sobre las colas de las histonas (Goers et al., 2003). Masliah y colaboradores (Masliah, Dumaop, Galasko, \& Desplats, 2013) hicieron un análisis de la metilación del DNA en la corteza frontal post mortem de pacientes con EP y en sus leucocitos. Encontraron que, tanto en el tejido cerebral como en la sangre, disminuían los niveles de metilación hasta un 89\%. El aporte grande de este estudio radica en la posibilidad de correlacionar los niveles de metilación en sangre y en tejido cerebral lo cual puede ayudar también en el diagnóstico de la EP.

\section{Factores microbianos}

Existe una línea reciente de investigación que parece demostrar una relación entre tipos particulares de toxinas producidas por parásitos y la aparición de EP e incluso de otras enfermedades neurodegenerativas. Vale la pena mencionar los trabajos de Brenner y colaboradores (2013), en los cuales se reporta una correlación entre la presencia de infección por ingesta de cianobacterias y el desarrollo de esclerosis lateral amiotrófica, enfermedad de Alzheimer y EP. De gran importancia resulta también el trabajo de Karlsson (2009) y colaboradores, en el cual se establece una relación entre la retención de beta- $\mathrm{N}$-metilamino-l-alanina (toxina producida por cianobacterias) y una clase de retinopatía pigmentaria presente en algunos pacientes de EP. Pero quizá el trabajo de mayor relevancia actual, sea el de Sampson y colaboradores (2016), quienes establecen una relación entre la presencia de ciertos microbios particulares en la microflora intestinal y el aumento de los síntomas parkinsónicos en ratones con una modificación genética que les aumenta la expresión de la alfa sinucleína. Su trabajo reporta también que, al tratar a estos animales con antibióticos selectivos, los síntomas mejoraron mientras que al implantarles microflora intestinal obtenidos de pacientes parkinsónicos, los síntomas empeoraban. Aparentemente el mecanismo por el cual este proceso actúa es por la producción de ácidos de cadena corta. Sin embargo, aún es muy temprano para extrapolar tratamientos antibióticos como tratamiento para casos de EP humana (Sampson et al., 2016). 


\section{Alternativas terapéuticas en enfermedad de Parkinson}

\section{Farmacológicas}

En la actualidad, el tratamiento más común para manejar los síntomas motores asociados a EP es la terapia con reemplazo de dopamina y/o con agonistas de dopamina (Lang, 2009; Obeso et al., 2010). Sin embargo; debido a la incapacidad de la dopamina para cruzar la barrera hematoencefálica, el tratamiento de referencia usado es con el precursor de dopamina Levodopa o L-Dopa (Mercuri \& Bernardi, 2005). Este precursor se metaboliza en dopamina por la acción de la di-hidroxifenilalanina descarboxilasa. El tratamiento con L-Dopa, mejora la calidad de vida de los pacientes tras aliviar los síntomas motores asociados a la depleción dopaminérgica (Geroin, Gandolfi, Bruno, Smania, \& Tinazzi, 2016; Manson, Stirpe, \& Schrag, 2012). No obstante, el tratamiento va perdiendo eficacia, posiblemente debido a que la muerte neuronal continúa, y por ello la dosificación ha de ser incrementada y es común que, tras el uso crónico por varios años, pierda su efectividad. Adicionalmente, tras el tratamiento crónico con L-Dopa (5-10 años) algunos efectos secundarios, tales como disquinesias se hacen manifiestos (Ahlskog \& Muenter, 2001). Las disquinesias afectan gravemente las actividades diarias de los pacientes incapacitándolos para continuar sus actividades laborales (WhettenGoldstein, Sloan, Kulas, Cutson, \& Schenkman, 1997). Por esas razones, el tratamiento con LDopa no es aconsejable como elección de primera mano, a menos que sea estrictamente necesario. Se prefiere iniciar el tratamiento con agonistas dopaminérgicos.

Algunas de las alternativas para prologar la eficacia de L-Dopa y aumentar el tiempo de aparición de las disquinesias o al menos disminuir su severidad, es a través la administración conjunta con inhibidores tanto de la catecol-0. metiltransferasa como de la monoaminooxidasa (MAO), o con Amantadina, por su papel como antagonista de receptores de tipo NMDA (Jankovic \& Stacy, 2007).

\section{Estimulación cerebral profunda (ECP)}

La gran aceptación para la utilización de la L-Dopa, para el tratamiento de la EP, desde inicios de 1970, se basó principalmente en la renuencia de pacientes y neurólogos hacia el uso de la cirugía estereotáxica para la ablación bien de porciones de los ganglios basales o bien de porciones talámicas. Esas cirugías eran utilizadas para el tratamiento de distonías y otros temblores (DeLong \& Wichmann, 2012; DeLong $\&$ Wichmann, 2015).

La cirugía estereotáxica actual para el control de desórdenes psiquiátricos o motores, ya no se basa en la ablación. En lugar de ello, se ha centrado en la estimulación eléctrica bien en áreas corticales o bien en áreas subcorticales. Esta última recibe el nombre de estimulación cerebral profunda (ECP o DBS, por sus iniciales en inglés). Los criterios de inclusión y los parámetros de estimulación para pacientes parkinsonianos que reciben ECP varían ampliamente de acuerdo a cada valoración neurológica en particular, pero se ha utilizado exitosamente para cuadros de trastorno obsesivo compulsivo (Benabid \& Torres, 2012; Kopell \& Greenberg, 2008; Rezai, 2009), epilepsia (Jaseja, Gupta, Jain, \& Gupta, 2014; Van et al., 2015; Mottonen et al., 2016), depresión (Cusin \& Dougherty, 2013; Okun et al., 2014; Berlim, McGirr, Van den Eynde, Fleck, \& Giacobbe, 2014; Quraan et al., 2014; Lilleeng, Gjerstad, Baardsen, Dalen, \& Larsen, 2015; Williams et al., 2016) y síndrome de Tourette (Visser-Vandewalle, Temel, van der Linden, Ackermans, \& Beuls, 2004; Sakas et al., 2007; Larson, 2008; Marks, Honeycutt, Acosta, $\&$ Reed, 2009).

Existe un consenso general que prescribe la cirugía para pacientes mayores de 60 años, en quienes el tratamiento farmacológico ha perdido eficacia. En algunos países, tales como Korea uno de los factores de inclusión es que la enfermedad tenga un curso mayor a tres años (Lee, 2015). Referente a los parámetros de estimulación, es 
muy importante mencionar que hasta la fecha no existe una estandarización universal acerca de las características óptimas de frecuencia, duración, corriente o intervalo interimpulso a utilizar en ECP para EP. De hecho, estos parámetros son fijados por el neurólogo a través de ensayo y error en cada paciente durante su cirugía o durante las visitas de control. Se ha visto que, por lo general, frecuencias mayores a $100 \mathrm{~Hz}$ con voltajes entre 2 y 3 volts han demostrado ser efectivas y son las comúnmente utilizadas (Blumenfeld et al., 2015).

El criterio de selección del área óptima para el implante del electrodo, es algo sobre lo cual tampoco existe un consenso. Las áreas objetivo más comúnmente utilizadas para realizar ECP en pacientes con EP, son el núcleo subtálamico (NST) y el globo pálido interno (GPi), ambas en abordaje bilateral. De forma interesante, la ablación de estas áreas tiene resultados similares a los obtenidos tras ECP (Okun, 2012; Okun $\&$ Foote, 2010), lo que permite suponer que, es posible que los efectos de la ECP sean el resultado de la depleción de neurotransmisor de algunas de las poblaciones celulares estimuladas, lo que simularía el efecto logrado por la lesión de las mismas. De igual manera, vale la pena mencionar que estas intervenciones alivian síntomas específicos de la enfermedad sin alterar o comprometer otras funciones. Una explicación para esto es que los ganglios basales están conformados por diferentes estructuras que trabajan de manera paralela e interconectada entre sí, a modo de circuitos, existiendo una división espacial entre ellos, lo que permite, en algunos casos, la intervención específica sobre uno de ellos, sin alterar el funcionamiento de los otros.

Uno de los circuitos motores de interés específico en EP es el que incluye el putamen, el núcleo caudado postcomisural y el área motora del NST. Se ha señalado que la depleción dopaminérgica crónica lleva a la disminución de la actividad inhibitoria de tipo GABAérgico en neuronas espinosas medianas y por consiguiente induce una mayor actividad glutamatérgica eferente de la corteza, lo que a su vez ocasiona una sobre activación de tipo excitatorio en el estriado (Albin, Price, Sakurai, Penney, \& Young, 1991; Albin et al., 1991). Esta desincronización eléctrica entre estructuras del estriado genera movimientos involuntarios y otras alteraciones motrices (Liang, DeLong, \& Papa, 2008; Antoniades et al., 2015).

Mediciones eléctricas en primates no humanos, han registrado una mayor tasa de disparo en neuronas del NST en pacientes parkinsónicos avanzados que en controles sanos $(13-30 \mathrm{~Hz}$ vs. $0.5-2 \mathrm{~Hz}$, respectivamente). Esta frecuencia de tipo beta en el NST exhibe una mayor potencia en la región dorsolateral en comparación con la región ventromedial (Yang, Vanegas, Lungu, \& Zaghloul, 2014). Esta actividad es regulada durante los primeros estadios de la enfermedad por L-Dopa. En estados avanzados puede ser regulada también por LDopa pero en conjunción con ECP (Liang et al., 2008; Brusa et al., 2001; Stefani et al., 2011).

A pesar de que ECP ha mostrado efectividad en el tratamiento de síntomas motores producto de esta desincronización eléctrica entre las estructuras del estriado, no existe total claridad acerca de los mecanismos por los cuales opera. No se sabe si las células eléctricamente estimuladas son de actividad aferente, eferente o una combinación de ambas (Antoniades et al., 2015). Se ha propuesto incluso que ECP ejerce estimulación bidireccional en las neuronas, de manera que se inducen potenciales de acción que viajan simultáneamente en dirección al axón y en dirección al soma celular. Como consecuencia, la estimulación eléctrica ejercería inhibición de la actividad glutamatérgica proveniente de la corteza, mientras que a su vez se eliminaría la actividad patológica de la neurona restableciendo la actividad normal de la misma, generando excitación a las proyecciones de la neurona o fibras cercanas al núcleo estimulado (Udupa \& Chen, 2015).

Se ha observado que pacientes que reciben ECP ya sea en el NST o GPi, presentan mejoría significativa a partir de los 6 a 12 meses (Rodriguez-Oroz et al., 2005; Dafsari et al., 2016) en síntomas motores asociados a EP (rigidez, temblor y bradiquinesia) en comparación con pacientes que reciben únicamente tratamiento 
farmacológico. Estos resultados son de gran relevancia debido al significativo impedimento motor presentado por los pacientes antes de recibir ECP. De igual manera, se ha reportado una increíble eficacia de ECP tras 4, 5 y 10 años post-operación (Rodriguez-Oroz, Moro, \& Krack, 2012; Jiang et al., 2015), sin embargo, su efectividad tras 5 y 10 años de estimulación no es tan acentuada como durante los primeros años luego del implante (Jiang et al., 2015).

La necesidad de reajuste en los parámetros de la estimulación es más frecuente en pacientes con ECP-NST que en aquellos con ECP-GPi, los cuales mantuvieron los mismos parámetros de estimulación tras una observación de cuatro años (Rodriguez-Oroz et al., 2005).

Es importante también mencionar que en ocasiones se han reportado efectos colaterales a los implantes para ECP, sin relación con la estimulación en sí, tales como, erosión de la piel o infección en el lugar donde la batería del estimulador se ha colocado, problemas con el estimulador, fractura del cable o infección en el lugar donde está dispuesto el mismo (DeLong \& Wichmann, 2015) o hematomas y hemorragias . A pesar de que estos eventos son de bajísima incidencia, pueden conducir a la discontinuidad del tratamiento ECP por parte de los pacientes y si bien, la edad del paciente parece no estar relacionada directamente con estas molestias, es evidente que las mismas son peormente toleradas por pacientes mayores de 65 años.

En resumen, ECP - ya sea en NST o GPi - es efectiva para mejorar síntomas motores, mejorar la capacidad autónoma del paciente con relación a sus actividades diarias y por consiguiente brindarle una mejor calidad de vida (Dafsari et al., 2016). La decisión entre ECP-NST o ECP-GPi ha de ser tomada de acuerdo a la sintomatología más clara presentada por el paciente. Si la prioridad es reducir la medicación dopaminérgica entonces ECP-NST es preferible, debido a que intervención en este núcleo disminuye la dosis diaria necesaria de L-Dopa hasta en un 50\%. Si se desea subir o mantener estable la dosis diaria de L-Dopa, ECP-GPi es una mejor opción (Okun \& Foote, 2010). Por otro lado, ECP-NST parece tener mayor efectividad en el control de síntomas motores en Parkinson mientras ECP-GPi tiene mayor efectividad en la reducción de disquinesia (Okun et al., 2014; Nowacki et al., 2015; Murchison, Fletcher, \& Cheeran, 2016). Sin embargo, efectos secundarios, tales como déficits cognoscitivos, dificultades de habla, desequilibrio y depresión, se presentan en mayor proporción en ECP-NST comparado con ECP-GPi (Lezcano et al., 2003; O'Sullivan \& Pell, 2009). Se ha demostrado que la ECp de alta frecuencia, reduce la severidad de los síntomas, reduce significativamente la necesidad del tratamiento farmacológico y mejora la percepción de calidad de vida de los propios pacientes (MartínezMartínez, Aguilar, \& Acevedo-Triana, 2016). Cabe recalcar que estos efectos secundarios pueden estar correlacionados con el estadio de la enfermedad per se y no necesariamente ser debidos a ECP. De hecho, muchos de los reportes carecen de información de línea base y, por consiguiente, los factores secundarios no pueden ser atribuidos claramente a ECP, a la medicación o al curso propio de la enfermedad. Algunas de las técnicas imagenológicas actuales, permiten conocer el estado dopaminérgico del paciente al momento de la evaluación, pudiendo ser utilizadas para confirmar el grado de evolución de la enfermedad y confirmar la causa de los efectos colaterales (Chen, Shih, \& Chang, 2013; Kahan et al., 2014).

Frecuencias superiores a $100 \mathrm{~Hz}$ son comúnmente utilizadas debido a su efectividad para aliviar los síntomas motores de la enfermedad. Blumenfeld y colaboradores (2015) encontraron que frecuencias de $60 \mathrm{~Hz}$ no sólo no tienen la capacidad de atenuar la característica frecuencia beta en el NST sino que incluso es capaz de incrementarla significativamente en pacientes con EP. En contraste a estos hallazgos, Vallabhajosula y su equipo (2015) reportan que la estimulación a $60 \mathrm{~Hz}$ en el NST tiene efectos moderadamente positivos en la corrección de déficits de la marcha; específicamente en pacientes que presentan un deterioro severo.

$\mathrm{Si}$ bien la ECP superior a $100 \mathrm{~Hz}$ es efectiva para aliviar temblores, rigidez y 
bradiquinesia, su uso crónico hace que algunas funciones tales como el habla y la marcha tiendan a empeorar. Una explicación para esto es que la estimulación continua a altas frecuencias ejerce una estimulación indirecta sobre estructuras adyacentes a NST (Stegemoller et al., 2013). Algunos avances tecnológicos recientes han dado paso a la estimulación cerebral profunda adaptable $(\mathrm{ECPa})$, la cual usa retroalimentación de las señales del cerebro para guiar la estimulación (Little et al., 2014; Little \& Bestmann, 2015). Con este tipo de retroalimentación el NST es estimulado únicamente cuando los sensores registran frecuencia beta. Los resultados muestran que ECPa es un tratamiento efectivo a la hora de aliviar los mismos síntomas motores que resuelve ECP, pero se muestra superior en relación a su eficacia, logrando reducir hasta un 50\% el tiempo de estimulación. Por consiguiente, se estima que los efectos secundarios generados por una continua estimulación de alta frecuencia en ECP estén ausentes en ECPa (Little et al., 2013; Priori, Foffani, Rossi, \& Marceglia, 2013; Little et al., 2014; Su et al., 2015; Arlotti, Rosa, Marceglia, Barbieri, \& Priori, 2016; Arlotti, Rossi, Rosa, Marceglia, \& Priori, 2016; Beudel \& Brown, 2016).

En conclusión, ECP ha mostrado ser altamente eficaz en reducir deficiencias motoras relacionadas a EP tales como temblor y bradiquinesia. Sus efectos a largo plazo son consistentes inclusive tras diez años postimplante, aunque éstos disminuyen levemente después de cinco años. Si bien ECP mejora significativamente la calidad de vida de los pacientes, hay síntomas a largo plazo que esta intervención no logra revertir.

\section{Implante neuronal}

Una de las alternativas terapéuticas que ha sido explorada y que en cierto sentido aún se puede considerar experimental es la técnica de transplante o implante neuronal. Los implantes iniciales eran realizados con células cromafines de la médula suprarrenal, generalmente de los propios pacientes (Mahanthappa, Gage, \& Patterson, 1990; Madrazo et al., 1989; Hansen, Notter, Okawara, \& Gash, 1988; Madrazo et al., 1987; Kordower, Cochran, Penn, \& Goetz, 1991; Olson et al., 1991). La investigación básica mostró que las células implantadas tenían una mejor sobrevida cuando eran colocadas en el interior de los ventrículos cerebrales que cuando eran implantadas directamente dentro del sistema nervioso, por lo general dentro del cuerpo estriado (Freed, Poltorak, \& Becker, 1990; Hansen, Bing, Notter, \& Gash, 1988; Mahanthappa et al., 1990). Se demostró también, en estos estudios iniciales, que la aplicación de BDNF podría ayudar a mantener con vida el implante. Sin embargo, su valor efectivo en la inclusión y mejoramiento en los circuitos funcionales en cuerpo estriado, o en la comunicación entre éste y otras estructuras del circuito cortico-estriado-talámico-cortical, no ha sido realmente evidenciada con este tipo de transplantes (Guridi, Herrero, Luquin, \& Obeso, 1991; Kupsch, Oertel, Earl, \& Sautter, 1995). De hecho, algunos reportes indican que quizá como máximo un 10\% de las neuronas implantadas, sobreviven al proceso mismo del implante (Brundin et al., 2000; Brundin \& Bjorklund, 1998) y que de ellas muy pocas llegan a incluirse funcionalmente en circuitos presentes (Hagell \& Brundin, 2001).

La utilización de autoimplantes de neuronas obtenidas a partir del ganglio cervical, también mostró poca integración con el tejido cerebral y una corta sobrevida del implante luego de la cirugía, lo cual desestimuló este tipo de trabajos desde una perspectiva clínica (Fernandez-Espejo, Armengol, Flores, Galan-Rodriguez, \& Ramiro, 2005).

También se realizaron implantes de neuronas, más específicamente, neuroblastos, obtenidos de mesencéfalos fetales, podían mantenerse con vida durante bastante tiempo luego de la cirugía de implante en cerebros adultos y que podían reinervar el estriado en modelos animales de Parkinson por aplicación de 6-OHDA. Esos reportes mostraban la recuperación de algunas funciones comportamentales (Dunnett, Bjorklund, Schmidt, Stenevi, \& Iversen, 1983; 
Dunnett et al., 1983; Dunnett, Bjorklund, Schmidt, Stenevi, \& Iversen, 1983; Annett et al., 1997). Estudios clínicos en humanos fueron realizados a partir de finales de la década de los 80s del siglo XX, utilizando tejido fetal de abortos, con algún éxito (Widner et al., 1992; Sawle et al., 1992). Naturalmente los aspectos éticos y prácticos asociados con la obtención del tejido para el implante, hicieron que esta línea de investigación entrara casi en desuso. También resulta importante mencionar que algunos de los pacientes que recibieron esos implantes, presentaron, cerca de dos décadas después, alteraciones motrices de tipo disquinesia, denominada "disquinesia inducida por el transplante" (Barker, Drouin-Ouellet, \& Parmar, 2015).

Una segunda oleada de investigación se suscitó desde la última década del siglo XX, gracias al advenimiento de los estudios con células madre pluri y multipotentes (Gerlach et al., 2002; Baetge, 1993; Wenker, Casalia, Candedo, Casabona, \& Pitossi, 2015; Zhu, Caldwell, \& Song, 2016; Astradsson \& Aziz, 2016). Igual que en el caso de los implantes de células cromafines de médula suprarrenal, en los implantes de células madre, es importante tomar en consideración el rol de los factores de crecimiento ya que existe la posibilidad de que, por un lado, la proliferación y la diferenciación del implante tome una dirección inadecuada o de que, por otro lado, los implantes no sobrevivan (Gash, Gerhardt, \& Hoffer, 1998; Shimoke \& Chiba, 2001; Farkas \& Krieglstein, 2002; Kim et al., 2006; Andereggen, Meyer, Guzman, Ducray, \& Widmer, 2009; Liu, Ma, Zhou, \& Xie, 2013; Deng et al., 2013). Sin embargo, parece ser que la viabilidad y sobrevida del implante es mayor para células madre, lo que ofrece un mejor panorama a futuro.

Debido a las restricciones éticas y prácticas para la obtención de determinados tipos de células madre, gran parte de la investigación actual se ha centrado en desarrollar nuevas formas de obtención de líneas celulares (Zhu et al., 2016). De esa forma, varias técnicas diferentes han sido empleadas para EP. Se han empleado células madre progenitoras de neuronas (NPCs) o células madre neuronales (NSCs), derivadas de células madre obtenidas de tejido embrionario. Previo al implante, estas células son tratadas in vitro con algunos factores tróficos tales como factor de crecimiento derivado de la glía (GDNF) o citokinas (Fricker-Gates \& Gates, 2010), los cuales conducen a las mayores tasas de sobrevida post implante, con alguna mejoría de los síntomas comportamentales. También se ha reportado que este procedimiento asegura el crecimiento neurítico hacia las dianas adeuadas (Wakeman et al., 2014). Uno de los factores que parece ayudar mucho al mantenimiento del implante, así como a la inclusión funcional de los implantes es el factor transcripcional Pitx3. Cuando éste está sobre-expresado en las NSCs, el implante se comporta mejor y hay una mayor recuperación funcional posterior (O'Keeffe et al., 2008; Chung et al., 2005; Lei, Jiang, Li, Zhu, \& Zeng, 2011).

El descubrimiento de que las neuronas dopaminérgicas de la substancia nigra proceden embriológicamente de la placa basal en oposición al resto de las neuronas encefálicas (Bonilla et al., 2008; Ono et al., 2007), permitió el desarrollo de nuevos protocolos de diferenciación que aumentan los tiempos de sobrevida del implante y reducen las posibilidades de generación de tumores (Barker et al., 2015).

El actual estado de avance en el diseño de protocolos de implante de células madre, conjuntamente con la disminución de las limitaciones basadas en juicios éticos y morales, hace prever que ésta sea quizá la técnica de mayor desarrollo a futuro y tal vez en ella podamos encontrar la cura definitiva, no sólo para EP sino para muchas otras enfermedades que aquejan a la humanidad.

\section{Factores de prevención}

Como fue mencionado antes, los estudios epidemiológicos han encontrado una alta correlación entre exposición a agentes pesticidas, metales pesados y la aparición de EP. Algunos otros estudios han demostrado una correlación inversa entre el alto consumo de café, el 
tabaquismo, el consumo de té y la aparición de EP (Liou et al., 1997; Breckenridge, Berry, Chang, Sielken, Jr., \& Mandel, 2016). En esta última sección se abordarán los efectos protectores de la nicotina y la cafeína en EP.

\section{Nicotina}

Desde muchas décadas atrás existen evidencias de la correlación inversa entre el consumo de tabaco y EP (Quik, 2004; Quik et al., 2009; Quik, Perez, \& Bordia, 2012; Bovet, Durel, \& Longo, 1950; Lechat \& Streichenberger, 1966; Kessler \& Diamond, 1971; Kessler, 1973; Das \& Ganguly, 1977; Haack, Baumann, McKean, Jameson, \& Turbek, 1981; Baron, 1986; Sershen, Hashim, \& Lajtha, 1987; Perry et al., 1987; Kirch, Alho, \& Wyatt, 1988). Algunos autores (Baumann, Jameson, McKean, Haack, \& Weisberg, 1980) han sugerido que la explicación de estos resultados es la mayor tasa de mortalidad en fumadores y no un efecto real de neuroprotección. Sin embargo, estudios prospectivos contradicen esta idea (Ross et al., 2000). Algunos otros autores, han encontrado menor incidencia de EP en fumadores pasivos que en no fumadores o no expuestos al humo de tabaco (Mellick, Gartner, Silburn, \& Battistutta, 2006). El objetivo más importante en esta línea de investigación es identificar el agente o los agentes del tabaco que proporcionan neuroprotección.

Diferentes estudios han mostrado que la estimulación de receptores nicotínicos (nAChRs) ubicados en neuronas dopaminérgicas aumenta la exocitosis de dopamina en el estriado (Wang et al., 2014; Janhunen \& Ahtee, 2007). También, en estudios post mortem se ha reportado disminución de $\mathrm{nAChRs}$ en diferentes áreas del cerebro en pacientes con EP (Rinne, Myllykyla, Lonnberg, \& Marjamaki, 1991), lo cual concuerda con estudios in vivo en los que a través de imágenes nucleares por tomografía por emisión de positrones (PET), se ha registrado perdida de nAChRs en diferentes áreas del cerebro, particularmente en la SN (14.9\%) en pacientes con EP (Kas et al., 2009). Por otro lado, la demencia presente en la EP podría estar relacionada con la disminución de la expresión de receptores colinérgicos en áreas corticales (Kas et al., 2009; Muller \& Bohnen, 2013).

En modelos animales, el estudio de los efectos de la nicotina inoculada sistémicamente, se desarrollan comúnmente a través de lesiones intracerebrales unilaterales en la SNc, ya sea con 6-OHDA o con MPTP (Blum et al., 2001; Schober, 2004; Luo et al., 2016; Abin-Carriquiry, McGregor-Armas, Costa, Urbanavicius, \& Dajas, 2002; Huang, Campos, Ly, Ivy, \& Quik, 2011; Quik, O'Neill, \& Perez, 2007). Estas lesiones conducen a un decremento de función dopaminérgica unilateral generando déficits motores en el lado contralateral a la inoculación del tóxico. Los modelos bilaterales no son usados debido a la baja expectativa de sobre vida post-quirúrgica. Además, la lesión unilateral ofrece la posibilidad de utilizar el lado no afectado como control. En estos modelos, la efectividad neuroprotectora de la nicotina se evalúa a través de mediciones de TH, transportadores de dopamina citoplasmáticos y vesiculares y mediante evaluaciones motoras y cognoscitivas (Janson \& Moller, 1993; Maggio et al., 1997; Garcia-Montes et al., 2012; Rahimmi, Khosrobakhsh, Izadpanah, Moloudi, \& Hassanzadeh, 2015).

Los resultados obtenidos en modelos animales no son contundentes, algunos muestran efectos protectores de la nicotina, otros reportan efectos adversos y otros no registran ningún efecto significativo (Garcia-Montes et al., 2012; Soto-Otero, Mendez-Alvarez, Sanchez-Sellero, Cruz-Landeira, \& Lopez-Rivadulla, 2001). Estas diferencias parecen depender de factores como la dosis de nicotina utilizada, la frecuencia y duración del tratamiento y el grado de lesión química realizada. El estudio de los reportes que aseguran un efecto neuroprotector, demuestra que la nicotina presenta una eficacia en forma de $\mathrm{U}$ invertida: dosis muy altas o muy bajas no generan protección nigroestriatal.

Vale la pena resaltar que el efecto de la nicotina es necesariamente de protección y no de restauración. El daño nigroestriatal es irreversible. Así, el tratamiento con nicotina 
antes y después de la lesión con $6 \mu \mathrm{g}$ de 6-OHDA previene el daño nigroestriatal, pero si la dosis utilizada de 6-OHDA es superior, la eficacia de la nicotina disminuye. Algunos autores reportan que cuando la nicotina es administrada después de la lesión, no se observa el efecto neuroprotectivo (Costa, Abin-Carriquiry, \& Dajas, 2001). De forma muy interesante, se ha reportado que tratamientos de nicotina durante las dos semanas anteriores a la lesión nigroestriatal aumentan la neuroprotección.

La eficacia de la nicotina también ha sido evaluada en humanos $y$, al igual que lo encontrado en modelos animales, no hay resultados consensuales. Algunos estudios han mostrado mejorías en los síntomas motores (Villafane et al., 2007), otros estudios no reportan ninguna mejoría (Vieregge, Sieberer, Jacobs, Hagenah, \& Vieregge, 2001) e incluso algunos otros han reportado empeoramiento en los síntomas (Ebersbach et al., 1999). Tal y como señalan Quik y Wonnacott en su revisión (2011), en estudios con menos de 16 participantes (informados del tipo de estudio) se encontró efectividad del tratamiento con nicotina; mientras que en estudios con una muestra mayor a 16 participantes (diseño doble ciego) no se encontró mejora en los síntomas luego del tratamiento con nicotina. Por estas razones los autores sugieren que un efecto placebo podría mediar la efectividad del tratamiento. Sin embargo, Thiriez y colaboradores (2011) apuntan que estas discrepancias pueden ser explicadas por el estadio de la enfermedad de los participantes incluidos en los estudios, los hábitos de fumar, la metodología de administración de la nicotina, su dosificación y duración de tratamiento; ya que al parecer estudios en fumadores muestran mejores resultados que en no fumadores. Adicionalmente, Villafane y colaboradores (2007) afirman que la administración transdérmica de nicotina en dosis crónicas (45 mg a $90 \mathrm{mg} /$ día) es efectiva para lograr mejoras a nivel cognitivo y motor. Esto podría explicar el bajo éxito de tratamientos con nicotina en otros estudios con menores dosis (Lemay et al., 2004).
En estudios in vitro se ha observado que la nicotina reduce la toxicidad en neuronas nigroestriatales, inhibiendo la agregación de \#-sinucleína y aumentando la expresión del citocromo P450, el cual desintegra los agentes tóxicos que contribuyen a la degeneración del sistema nigroestriatal (Miksys \& Tyndale, 2006).

Uno de los efectos conocidos de la administración crónica de L-Dopa es el daño al sistema serotoninérgico. Este daño ha sido asociado con la aparición de disquinesias (Munoz et al., 2008). Estudios con nicotina demuestran que ésta es capaz de revertir tales daños mediante la modulación del sistema serotoninérgico (Quik et al., 2007).

A pesar que los mecanismos de neuroprotección de la nicotina no son totalmente claros, algunos estudios siguieren que tales efectos deben ser mediados por la combinación de subunidades \#4\#2 y \#6\#2 de los receptores nicotínicos (Quik \& Wonnacott, 2011). Los receptores que poseen dichas subunidades están localizados en las neuronas dopaminérgicas que van de $\mathrm{SN}$ al estriado. Además, en la SN existen aferencias colinérgicas y en el estriado hay interneuronas colinérgicas, así, parte de la regulación de la ruta nigroestriatal está mediada por la acetilcolina.

Receptores \#4\#2 también se encuentran en terminales GABAérgicas en las neuronas espinosas medias del estriado, interneuronas en la SN, estriado y globo pálido.

Parte de las discrepancias encontradas en los resultados de estudios sobre el efecto neuroprotector de la nicotina para EP, tanto en modelos animales como en humanos, podría ser explicada por las metodologías usadas en cada estudio o por la velocidad con que la nicotina es metabolizada en diferentes especies. En cualquier caso, se requieren mayores estudios experimentales a este respecto.

\section{Cafeína}

La cafeína hace parte del grupo de metilxantinas, siendo por tanto un estimulante del sistema nervioso central. Tiene un aparente rol en el 
aumento de la neurotransmisión dopaminérgica actuando como antagonista de los receptores de adenosina. Los receptores de adenosina se expresan principalmente en putamen, globo pálido, núcleo caudado y núcleo accumbens. Las investigaciones sobre el papel de la cafeína sobre el curso de EP han centrado su atención en el estudio del receptor de adenosina subtipo $\mathrm{A}_{2 \mathrm{~A}}$ (Chen, 2014; Ferreira et al., 2015; Michel et al., 2015).

En trabajos experimentales con animales diferentes al humano, se ha reportado menor actividad motriz cuando los receptores de adenosina son estimulados, lo que puede deberse a la disminución de la liberación de dopamina que se produce con la activación de receptores $\mathrm{A}_{2 \mathrm{~A}}$ (Jenner, 2014) por consiguiente, puede pensarse que es posible lograr una mayor liberación de dopamina con el bloqueo de estos mismos receptores. Adicionalmente, se ha reportado rotación contralateral inducida por cafeína y otros antagonistas de adenosina (como por ejemplo el KW-6002) en modelos animales de EP inducida por 6-OHDA y MPTP (Koga, Kurokawa, Ochi, Nakamura, \& Kuwana, 2000; Kase et al., 2003). En otras investigaciones se ha demostrado que los antagonistas de receptores $A_{2 A}$ poseen efectos neuroprotectores reduciendo, por ejemplo, la probabilidad de formación de tumores en el cerebro (Varani et al., 2010) y disminuyendo la perdida dopaminérgica inducida por MPTP (Xu, Xu, Chen, \& Schwarzschild, 2010).

Por otro lado, mejoras en la sintomatología motora también ha sido reportada en ensayos con humanos y en roedores (Kalda, Yu, Oztas, \& Chen, 2006; Prediger, 2010), indicando una potencial eficacia de los antagonistas $\mathrm{A}_{2 \mathrm{~A}}$ en el tratamiento de síntomas motores en la EP. Esto sugeriría que pacientes con EP, que consumen café, necesitan una menor dosis de L-Dopa que aquellos que no consumen café, pero al parecer no hay relación entre el consumo de cafeína y el curso de la enfermedad (Schwarzschild, Chen, \& Ascherio, 2002; Palacios et al., 2012). De hecho, existe evidencia sugiere que la cafeína altera la farmacodinámica y la farmacocinética del L-
Dopa (Deleu, Jacob, Chand, Sarre, \& Colwell, 2006).

\section{Conclusión}

El primer caso diagnosticado con EP fue en el año 1817, desde entonces y hasta la fecha miles de nuevos casos se reportan a diario. Se estima que para 2030 la población afectada por la enfermedad sea el doble de la actual en 2016 (Dorsey et al., 2007; Achey et al., 2014). La causa directa de la EP es atribuida a la muerte progresiva de las neuronas dopaminérgicas en la $\mathrm{SN}$, sin embargo, aún no se sabe con plena certeza cuáles son las variables ambientales, genéticas ni las interacciones entre ellas que llevan a esta destrucción celular masiva. Se sabe que la exposición prolongada a algunos agrotóxicos y a algunos metales, puede aumentar el riesgo de desarrollo de la enfermedad, pero aún no se ha determinado esta relación con claridad.

Actualmente no existe cura para EP. El tratamiento de preferencia, L-Dopa, sólo o acompañado por agonistas dopaminérgicos, es efectivo para tratar los síntomas motores asociados a la depleción dopaminérgica, característica de la enfermedad. Sin embargo, debido a que EP se debe principalmente a la muerte progresiva e irrefrenable de las neuronas dopaminérgicas en la SN, la efectividad de LDopa decae con el paso del tiempo, además de inducir la aparición de efectos secundarios como disquinesias.

Tratamientos más recientes, tales como la ECP y ECPa son altamente eficientes en tratar los síntomas motores inclusive cuando los tratamientos farmacológicos son ineficaces. Estos resultados han hecho que estos tratamientos sean incluidos y financiados por los servicios de salud pública de diferentes países. No obstante, aún existen múltiples limitaciones de las técnicas de estimulación, debidas a la carencia de un conocimiento claro y preciso de la forma en que funcionan. Por esa razón, es fundamental el estudio sistemático de estas técnicas en modelos animales de EP. 
Desde el punto de vista de las aproximaciones terapéuticas, las técnicas de implante celular, sean, quizá, las de mayor alcance. El estado actual de desarrollo en protocolos de cultivo y diferenciación celular, permite suponer que, en pocos años, se tendrá la capacidad de realizar implantes capaces de sobrevivir e integrarse funcionalmente.

Los estudios sobre los mecanismos de acción de agentes neuroprotectores de la EP, tales como la nicotina y la cafeína, están siendo de gran utilidad en el desarrollo de agentes con alta especificidad para receptores $n A c h R s$ (que incluyan las subunidades \#4\#2, \#6\#2) y para receptores antagonistas $A_{2 A}$.

Debido a la ausencia de una cura para la EP, todos los esfuerzos actuales están siendo dirigidos a la creación de tratamientos que logren al menos frenar el curso de la enfermedad, o a de ser posible - revertir el daño ya instaurado y a prevenir el avance de la patología en personas con mayor probabilidad de desarrollar la enfermedad.

\section{Referencias}

Abin-Carriquiry, J. A., McGregor-Armas, R., Costa, G., Urbanavicius, J., \& Dajas, F. (2002). Presynaptic involvement in the nicotine prevention of the dopamine loss provoked by 6 -OHDA administration in the substantia nigra. Neurotox.Res., 4, 133-139.

Achey, M., Aldred, J. L., Aljehani, N., Bloem, B. R., Biglan, K. M., Chan, P. et al. (2014). The past, present, and future of telemedicine for Parkinson's disease. Mov Disord., 29, 871-883.

Ahlskog, J. E. \& Muenter, M. D. (2001). Frequency of levodopa-related dyskinesias and motor fluctuations as estimated from the cumulative literature. Mov Disord., 16, 448-458.

Albin, R. L., Price, R. H., Sakurai, S. Y., Penney, J. B., \& Young, A. B. (1991). Excitatory and inhibitory amino acid binding sites in human dentate nucleus. Brain Res., 560, 350-353.

Albin, R. L., Sakurai, S. Y., Makowiec, R. L., Higgins, D. S., Young, A. B., \& Penney, J. B. (1991). Excitatory amino acid, GABA(A), and $\mathrm{GABA}(\mathrm{B})$ binding sites in human striate cortex. Cereb.Cortex, 1, 499-509.

Andereggen, L., Meyer, M., Guzman, R., Ducray, A. D., \& Widmer, H. R. (2009). Effects of GDNF pretreatment on function and survival of transplanted fetal ventral mesencephalic cells in the 6-OHDA rat model of Parkinson's disease. Brain Res., 1276, 39-49.

Annett, L. E., Torres, E. M., Clarke, D. J., Ishida, Y., Barker, R. A., Ridley, R. M. et al. (1997). Survival of nigral grafts within the striatum of marmosets with 6-OHDA lesions depends critically on donor embryo age. Cell Transplant., 6, 557-569.

Antoniades, C. A., Rebelo, P., Kennard, C., Aziz, T. Z., Green, A. L., \& FitzGerald, J. J. (2015). Pallidal Deep Brain Stimulation Improves Higher Control of the Oculomotor System in Parkinson's Disease. J.Neurosci., 35, 13043-13052.

Arlotti, M., Rosa, M., Marceglia, S., Barbieri, S., \& Priori, A. (2016). The adaptive deep brain stimulation challenge. Parkinsonism.Relat Disord., 28, 12-17.

Arlotti, M., Rossi, L., Rosa, M., Marceglia, S., \& Priori, A. (2016). An external portable device for adaptive deep brain stimulation (aDBS) clinical research in advanced Parkinson's Disease. Med.Eng Phys., 38, 498-505.

Astradsson, A. \& Aziz, T. (2016). Parkinson's disease: fetal cell or stem cell derived treatments. BMJ, 352, h6340.

Baetge, E. E. (1993). Neural stem cells for CNS transplantation. Ann.N.Y.Acad.Sci., 695, 285-291.

Barker, R. A., Drouin-Ouellet, J., \& Parmar, M. (2015). Cell-based therapies for Parkinson disease-past insights and future potential. Nat.Rev.Neurol., 11, 492-503. 
Baron, J. A. (1986). Cigarette smoking and Parkinson's disease. Neurology, 36, 1490-1496.

Bartels, A. L. \& Leenders, K. L. (2009). Parkinson's disease: the syndrome, the pathogenesis and pathophysiology. Cortex, 45, 915-921.

Bashkatova, V., Alam, M., Vanin, A., \& Schmidt, W. J. (2004). Chronic administration of rotenone increases levels of nitric oxide and lipid peroxidation products in rat brain. Exp.Neurol., 186, 235-241.

Baumann, R. J., Jameson, H. D., McKean, H. E., Haack, D. G., \& Weisberg, L. M. (1980). Cigarette smoking and Parkinson disease: 1. Comparison of cases with matched neighbors. Neurology, 30, 839-843.

Benabid, A. L. \& Torres, N. (2012). New targets for DBS. Parkinsonism.Relat Disord., 18 Suppl 1, S21-S23.

Berlim, M. T., McGirr, A., Van den Eynde, F., Fleck, M. P., \& Giacobbe, P. (2014). Effectiveness and acceptability of deep brain stimulation (DBS) of the subgenual cingulate cortex for treatment-resistant depression: a systematic review and exploratory meta-analysis. J.Affect.Disord., 159, 31-38.

Betarbet, R., Sherer, T. B., MacKenzie, G., Garcia-Osuna, M., Panov, A. V., \& Greenamyre, J. T. (2000). Chronic systemic pesticide exposure reproduces features of Parkinson's disease. Nat.Neurosci., 3, 1301-1306.

Beudel, M. \& Brown, P. (2016). Adaptive deep brain stimulation in Parkinson's disease. Parkinsonism.Relat Disord., 22 Suppl 1, S123S126.

Blum, D., Torch, S., Lambeng, N., Nissou, M., Benabid, A. L., Sadoul, R. et al. (2001). Molecular pathways involved in the neurotoxicity of 6-OHDA, dopamine and MPTP: contribution to the apoptotic theory in Parkinson's disease. Prog.Neurobiol., 65, 135-172.

Blumenfeld, Z., Velisar, A., Miller, K. M., Hill, B. C., Shreve, L. A., Quinn, E. J. et al. (2015). Sixty hertz neurostimulation amplifies subthalamic neural synchrony in Parkinson's disease. PLoS.One., 10, e0121067.

Bonilla, S., Hall, A. C., Pinto, L., Attardo, A., Gotz, M., Huttner, W. B. et al. (2008). Identification of midbrain floor plate radial glia-like cells as dopaminergic progenitors. Glia, 56, 809-820.

Bovet, D., Durel, P., \& Longo, V. (1950). [Antagonism of dibenzothiazine derivatives (diparcol, parsidol, phenergan) towards the central effects of nicotine; correspondence with clinical experimentation in Parkinson's disease]. C.R.Seances Soc.Biol.Fil., 144, 514-517.

Braithwaite, S. P., Stock, J. B., \& Mouradian, M. M. (2012). alpha-Synuclein phosphorylation as a therapeutic target in Parkinson's disease. Rev.Neurosci., 23, 191-198.

Breckenridge, C. B., Berry, C., Chang, E. T., Sielken, R. L., Jr., \& Mandel, J. S. (2016). Association between Parkinson's Disease and Cigarette Smoking, Rural Living, Well-Water Consumption, Farming and Pesticide Use: Systematic Review and Meta-Analysis. PLoS.One., 11, e0151841.

Brenner, S. R. (2013). Blue-green algae or cyanobacteria in the intestinal microflora may produce neurotoxins such as Beta-N-Methylamino-L-Alanine (BMAA) which may be related to development of amyotrophic lateral sclerosis, Alzheimer's disease and Parkinson-Dementia-Complex in humans and Equine Motor Neuron Disease in horses. Med.Hypotheses, 80, 103.

Bretaud, S., Lee, S., \& Guo, S. (2004). Sensitivity of zebrafish to environmental toxins implicated in Parkinson's disease. Neurotoxicol.Teratol., 26, 857-864.

Brundin, P. \& Bjorklund, A. (1998). Survival of expanded dopaminergic precursors is critical for clinical trials. Nat.Neurosci., 1, 537.

Brundin, P., Karlsson, J., Emgard, M., Schierle, G. S., Hansson, O., Petersen, A. et al. (2000). Improving the survival of grafted dopaminergic neurons: a review 
over current approaches. Cell Transplant., 9, 179-195.

Brusa, L., Pierantozzi, M., Peppe, A., Altibrandi, M. G., Giacomini, P., Mazzone, P. et al. (2001). Deep brain stimulation (DBS) attentional effects parallel those of 1-dopa treatment. J.Neural Transm.(Vienna.), 108, 1021-1027.

Carpenter, D. O. (2001). Effects of metals on the nervous system of humans and animals. Int.J.Occup.Med.Environ. Health, 14, 209-218.

Chen, C. C., Shih, Y. Y., \& Chang, C. (2013). Dopaminergic imaging of nonmotor manifestations in a rat model of Parkinson's disease by fMRI. Neurobiol.Dis., 49, 99-106.

Chen, J. F. (2014). Adenosine receptor control of cognition in normal and disease. Int.Rev.Neurobiol., 119, 257-307.

Chen, L., Xie, Z., Turkson, S., \& Zhuang, X. (2015). A53T human alpha-synuclein overexpression in transgenic mice induces pervasive mitochondria macroautophagy defects preceding dopamine neuron degeneration. J.Neurosci., 35, 890-905.

Chung, S., Hedlund, E., Hwang, M., Kim, D. W., Shin, B. S., Hwang, D. Y. et al. (2005). The homeodomain transcription factor Pitx3 facilitates differentiation of mouse embryonic stem cells into AHD2expressing dopaminergic neurons. Mol.Cell Neurosci., 28, 241-252.

Chwiej, J., Adamek, D., SzczerbowskaBoruchowska, M., Krygowska-Wajs, A., Bohic, S., \& Lankosz, M. (2008). Study of $\mathrm{Cu}$ chemical state inside single neurons from Parkinson's disease and control substantia nigra using the microXANES technique. J.Trace Elem.Med.Biol., 22, 183-188.

Coppede, F., Tannorella, P., Stoccoro, A., Chico, L., Siciliano, G., Bonuccelli, U. et al. (2016). Methylation analysis of DNA repair genes in Alzheimer's disease. Mech.Ageing Dev..

Costa, G., Abin-Carriquiry, J. A., \& Dajas, F. (2001). Nicotine prevents striatal dopamine loss produced by 6 hydroxydopamine lesion in the substantia nigra. Brain Res., 888, 336-342.

Cusin, C. \& Dougherty, D. D. (2013). Correction: Somatic therapies for treatment-resistant depression: ECT, TMS, VNS, DBS. Biol.Mood.Anxiety.Disord., 3, 1.

Dafsari, H. S., Reddy, P., Herchenbach, C., Wawro, S., Petry-Schmelzer, J. N., Visser-Vandewalle, V. et al. (2016). Beneficial Effects of Bilateral Subthalamic Stimulation on Non-Motor Symptoms in Parkinson's Disease. Brain Stimul., 9, 78-85.

Das, M. \& Ganguly, D. K. (1977). Interactions of some cholinolytic anti-parkinson drugs with nicotine and oxotremorine on rat diaphragm. Toxicol.Appl.Pharmacol., 39, 149-152.

Deleu, D., Jacob, P., Chand, P., Sarre, S., \& Colwell, A. (2006). Effects of caffeine on levodopa pharmacokinetics and pharmacodynamics in Parkinson disease. Neurology, 67, 897-899.

DeLong, M. \& Wichmann, T. (2012). Deep brain stimulation for movement and other neurologic disorders. Ann.N.Y.Acad.Sci., $1265,1-8$.

DeLong, M. R. \& Wichmann, T. (2015). Basal Ganglia Circuits as Targets for Neuromodulation in Parkinson Disease. JAMA Neurol., 72, 1354-1360.

Deng, X., Liang, Y., Lu, H., Yang, Z., Liu, R., Wang, J. et al. (2013). Co-transplantation of GDNF-overexpressing neural stem cells and fetal dopaminergic neurons mitigates motor symptoms in a rat model of Parkinson's disease. PLoS.One., 8, e80880.

Dexter, D. T., Wells, F. R., Lees, A. J., Agid, F., Agid, Y., Jenner, P. et al. (1989). Increased nigral iron content and alterations in other metal ions occurring in brain in Parkinson's disease. J.Neurochem., 52, 1830-1836.

Dorsey, E. R., Constantinescu, R., Thompson, J. P., Biglan, K. M., Holloway, R. G., Kieburtz, K. et al. (2007). Projected number of people with Parkinson disease in the most populous nations, 2005 through 2030. Neurology, 68, 384-386. 
Drolet, R. E., Cannon, J. R., Montero, L., \& Greenamyre, J. T. (2009). Chronic rotenone exposure reproduces Parkinson's disease gastrointestinal neuropathology. Neurobiol.Dis., 36, 96-102.

Dunnett, S. B., Bjorklund, A., Schmidt, R. H., Stenevi, U., \& Iversen, S. D. (1983). Intracerebral grafting of neuronal cell suspensions. IV. Behavioural recovery in rats with unilateral 6-OHDA lesions following implantation of nigral cell suspensions in different forebrain sites. Acta Physiol Scand.Suppl, 522, 29-37.

Dunnett, S. B., Bjorklund, A., Schmidt, R. H., Stenevi, U., \& Iversen, S. D. (1983). Intracerebral grafting of neuronal cell suspensions. V. Behavioural recovery in rats with bilateral 6-OHDA lesions following implantation of nigral cell suspensions. Acta Physiol Scand.Suppl, 522, 39-47.

Ebersbach, G., Stock, M., Muller, J., Wenning, G., Wissel, J., \& Poewe, W. (1999). Worsening of motor performance in patients with Parkinson's disease following transdermal nicotine administration. Mov Disord., 14, 1011-1013.

Farkas, L. M. \& Krieglstein, K. (2002). Heparin-binding epidermal growth factorlike growth factor (HB-EGF) regulates survival of midbrain dopaminergic neurons. J.Neural Transm.(Vienna.), 109, 267-277.

Fernandez-Espejo, E., Armengol, J. A., Flores, J. A., Galan-Rodriguez, B., \& Ramiro, S. (2005). Cells of the sympathoadrenal lineage: biological properties as donor tissue for cell-replacement therapies for Parkinson's disease. Brain Res.Brain Res.Rev., 49, 343-354.

Ferreira, D. G., Batalha, V. L., Vicente, M. H., Coelho, J. E., Gomes, R., Goncalves, F. Q. et al. (2015). Adenosine A2A Receptors Modulate alpha-Synuclein Aggregation and Toxicity. Cereb.Cortex.

Freed, W. J., Poltorak, M., \& Becker, J. B. (1990). Intracerebral adrenal medulla grafts: a review. Exp.Neurol., 110, 139-166.

Fricker-Gates, R. A. \& Gates, M. A. (2010). Stem cell-derived dopamine neurons for brain repair in Parkinson's disease. Regen.Med., 5, 267-278.

Gao, H. M., Hong, J. S., Zhang, W., \& Liu, B. (2003). Synergistic dopaminergic neurotoxicity of the pesticide rotenone and inflammogen lipopolysaccharide: relevance to the etiology of Parkinson's disease. J.Neurosci., 23, 1228-1236.

Garcia-Montes, J. R., Boronat-Garcia, A., Lopez-Colome, A. M., Bargas, J., GuerraCrespo, M., \& Drucker-Colin, R. (2012). Is nicotine protective against Parkinson's disease? An experimental analysis. CNS.Neurol.Disord.Drug Targets., 11, 897-906.

Gash, D. M., Gerhardt, G. A., \& Hoffer, B. J. (1998). Effects of glial cell line-derived neurotrophic factor on the nigrostriatal dopamine system in rodents and nonhuman primates. Adv.Pharmacol., 42, 911-915.

Gerlach, M., Braak, H., Hartmann, A., Jost, W. H., Odin, P., Priller, J. et al. (2002). Current state of stem cell research for the treatment of Parkinson's disease. J.Neurol., 249 Suppl 3, III/33-III/35.

Geroin, C., Gandolfi, M., Bruno, V., Smania, N., \& Tinazzi, M. (2016). Integrated Approach for Pain Management in Parkinson Disease. Curr.Neurol.Neurosci.Rep., 16, 28.

Glover, V., Gibb, C., \& Sandler, M. (1986). The role of MAO in MPTP toxicity--a review. J.Neural Transm.Suppl, 20, 65-76.

Goers, J., Manning-Bog, A. B., McCormack, A. L., Millett, I. S., Doniach, S., Di Monte, D. A. et al. (2003). Nuclear localization of alpha-synuclein and its interaction with histones. Biochemistry, 42, 8465-8471.

Gorell, J. M., Peterson, E. L., Rybicki, B. A., \& Johnson, C. C. (2004). Multiple risk factors for Parkinson's disease. J.Neurol.Sci., 217, 169-174.

Gorell, J. M., Rybicki, B. A., Cole, J. C., \& Peterson, E. L. (1999). Occupational metal exposures and the risk of Parkinson's disease. Neuroepidemiology, 18, 303-308.

Guridi, J., Herrero, M. T., Luquin, M. R., \& Obeso, J. A. (1991). [Cellular transplants 
for Parkinson's disease]. Neurologia, 6, 175-183.

Haack, D. G., Baumann, R. J., McKean, H. E., Jameson, H. D., \& Turbek, J. A. (1981). Nicotine exposure and Parkinson disease. Am.J.Epidemiol., 114, 191-200.

Hagell, P. \& Brundin, P. (2001). Cell survival and clinical outcome following intrastriatal transplantation in Parkinson disease. J.Neuropathol.Exp.Neurol., 60, 741-752.

Haggerty, T., Credle, J., Rodriguez, O., Wills, J., Oaks, A. W., Masliah, E. et al. (2011). Hyperphosphorylated Tau in an alphasynuclein-overexpressing transgenic model of Parkinson's disease. Eur.J.Neurosci., 33, 1598-1610.

Hansen, J. T., Bing, G. Y., Notter, M. F., \& Gash, D. M. (1988). Paraneuronal grafts in unilateral 6-hydroxydopamine-lesioned rats: morphological aspects of adrenal chromaffin and carotid body glomus cell implants. Prog.Brain Res., 78, 507-511.

Hansen, J. T., Notter, M. F., Okawara, S. H., \& Gash, D. M. (1988). Organization, fine structure, and viability of the human adrenal medulla: considerations for neural transplantation. Ann.Neurol., 24, 599-609.

Huang, L. Z., Campos, C., Ly, J., Ivy, C. F., \& Quik, M. (2011). Nicotinic receptor agonists decrease Ldopa-induced dyskinesias most effectively in partially lesioned parkinsonian rats. Neuropharmacology, 60, 861-868.

Janhunen, S. \& Ahtee, L. (2007). Differential nicotinic regulation of the nigrostriatal and mesolimbic dopaminergic pathways: implications for drug development. Neurosci.Biobehav.Rev., 31, 287-314.

Jankovic, J. \& Stacy, M. (2007). Medical management of levodopa-associated motor complications in patients with Parkinson's disease. CNS.Drugs, 21, 677-692.

Janson, A. M. \& Moller, A. (1993). Chronic nicotine treatment counteracts nigral cell loss induced by a partial mesodiencephalic hemitransection: an analysis of the total number and mean volume of neurons and glia in substantia nigra of the male rat. Neuroscience, 57, 931-941.

Jaseja, H., Gupta, A., Jain, R., \& Gupta, P. (2014). Intractable epilepsy: deep brain stimulation (DBS)-based electrophysiological biomarker. Epilepsy Behav., 31, 13-14.

Jenner, P. (2014). An overview of adenosine A2A receptor antagonists in Parkinson's disease. Int.Rev.Neurobiol., 119, 71-86.

Jiang, L. L., Liu, J. L., Fu, X. L., Xian, W. B., Gu, J., Liu, Y. M. et al. (2015). Longterm Efficacy of Subthalamic Nucleus Deep Brain Stimulation in Parkinson's Disease: A 5-year Follow-up Study in China. Chin Med.J.(Engl.), 128, 2433-2438.

Jinsmaa, Y., Sullivan, P., Gross, D., Cooney, A., Sharabi, Y., \& Goldstein, D. S. (2014). Divalent metal ions enhance DOPAL-induced oligomerization of alphasynuclein. Neurosci.Lett., 569, 27-32.

Jowaed, A., Schmitt, I., Kaut, O., \& Wullner, U. (2010). Methylation regulates alphasynuclein expression and is decreased in Parkinson's disease patients' brains. J.Neurosci., 30, 6355-6359.

Kahan, J., Urner, M., Moran, R., Flandin, G., Marreiros, A., Mancini, L. et al. (2014). Resting state functional MRI in Parkinson's disease: the impact of deep brain stimulation on 'effective' connectivity. Brain, 137, 1130-1144.

Kalda, A., Yu, L., Oztas, E., \& Chen, J. F. (2006). Novel neuroprotection by caffeine and adenosine $\mathrm{A}(2 \mathrm{~A})$ receptor antagonists in animal models of Parkinson's disease. J.Neurol.Sci., 248, 9-15.

Karlsson, O., Berg, C., Brittebo, E. B., \& Lindquist, N. G. (2009). Retention of the cyanobacterial neurotoxin beta- $\mathrm{N}$ methylamino-l-alanine in melanin and neuromelanin-containing cells--a possible link between Parkinson-dementia complex and pigmentary retinopathy. Pigment Cell Melanoma Res., 22, 120-130.

Kas, A., Bottlaender, M., Gallezot, J. D., Vidailhet, M., Villafane, G., Gregoire, M. C. et al. (2009). Decrease of nicotinic 
receptors in the nigrostriatal system in Parkinson's disease. J.Cereb.Blood Flow Metab, 29, 1601-1608.

Kase, H., Aoyama, S., Ichimura, M., Ikeda, K., Ishii, A., Kanda, T. et al. (2003). Progress in pursuit of therapeutic A2A antagonists: the adenosine A2A receptor selective antagonist KW6002: research and development toward a novel nondopaminergic therapy for Parkinson's disease. Neurology, 61, S97-100.

Kessler, I. I. (1973). Parkinson's disease perspectives on epidemiology and pathogenesis. Prev.Med., 2, 88-105.

Kessler, I. I. \& Diamond, E. L. (1971). Epidemiologic studies of Parkinson's disease. I. Smoking and Parkinson's disease: a survey and explanatory hypothesis. Am.J.Epidemiol., 94, 16-25.

Kim, S. U., Park, I. H., Kim, T. H., Kim, K. S., Choi, H. B., Hong, S. H. et al. (2006). Brain transplantation of human neural stem cells transduced with tyrosine hydroxylase and GTP cyclohydrolase 1 provides functional improvement in animal models of Parkinson disease. Neuropathology., 26, 129-140.

Kirch, D. G., Alho, A. M., \& Wyatt, R. J. (1988). Hypothesis: a nicotinedopamine interaction linking smoking with Parkinson's disease and tardive dyskinesia. Cell Mol.Neurobiol., 8, 285-291.

Koga, K., Kurokawa, M., Ochi, M., Nakamura, J., \& Kuwana, Y. (2000). Adenosine A(2A) receptor antagonists KF17837 and KW-6002 potentiate rotation induced by dopaminergic drugs in hemi-Parkinsonian rats. Eur.J.Pharmacol., 408, 249-255.

Kontopoulos, E., Parvin, J. D., \& Feany, M. B. (2006). Alpha-synuclein acts in the nucleus to inhibit histone acetylation and promote neurotoxicity. Hum.Mol.Genet., 15, 3012-3023.

Kopell, B. H. \& Greenberg, B. D. (2008). Anatomy and physiology of the basal ganglia: implications for DBS in psychiatry. Neurosci.Biobehav.Rev., 32, 408-422.
Kordower, J. H., Cochran, E., Penn, R. D., \& Goetz, C. G. (1991). Putative chromaffin cell survival and enhanced host-derived $\mathrm{TH}$-fiber innervation following a functional adrenal medulla autograft for Parkinson's disease. Ann.Neurol., 29, 405-412.

Kumar, K. R., Djarmati-Westenberger, A., \& Grunewald, A. (2011). Genetics of Parkinson's disease. Semin.Neurol., 31, 433-440.

Kumudini, N., Uma, A., Devi, Y. P., Naushad, S. M., Mridula, R., Borgohain, R. et al. (2014). Association of Parkinson's disease with altered serum levels of lead and transition metals among South Indian subjects. Indian J.Biochem.Biophys., 51, 121-126.

Kupsch, A., Oertel, W. H., Earl, C. D., \& Sautter, J. (1995). Neuronal transplantation and neurotrophic factors in the treatment of Parkinson's disease--update February 1995. J.Neural Transm.Suppl, 46, 193-207.

Laing, N. (2001). Genes and brains, molecular medicine and neuropathology. Trends Mol.Med., 7, 6-7.

Lang, A. E. (2009). When and how should treatment be started in Parkinson disease? Neurology, 72, S39-S43.

Langston, J. W., Langston, E. B., \& Irwin, I. (1984). MPTP-induced parkinsonism in human and non-human primates-clinical and experimental aspects. Acta Neurol.Scand.Suppl, 100, 49-54.

Lansbury, P. T., Jr. \& Brice, A. (2002). Genetics of Parkinson's disease and biochemical studies of implicated gene products. Curr.Opin.Cell Biol., 14, 653-660.

Larson, P. S. (2008). Deep brain stimulation for psychiatric disorders. Neurotherapeutics., 5, 50-58.

Lechat, P. \& Streichenberger, G. (1966). [Pharmacologic study of the possible anti-Parkinson effect of chlormethiazole]. Therapie, 21, 1617-1621.

Lee, J. I. (2015). The Current Status of Deep Brain Stimulation for the Treatment of Parkinson Disease in the Republic of Korea. J.Mov Disord., 8, 115-121. 
Lei, Z., Jiang, Y., Li, T., Zhu, J., \& Zeng, S. (2011). Signaling of glial cell line-derived neurotrophic factor and its receptor GFRalpha1 induce Nurr1 and Pitx3 to promote survival of grafted midbrain-derived neural stem cells in a rat model of Parkinson disease. J.Neuropathol.Exp.Neurol., 70, 736-747.

Lemay, S., Chouinard, S., Blanchet, P., Masson, H., Soland, V., Beuter, A. et al. (2004). Lack of efficacy of a nicotine transdermal treatment on motor and cognitive deficits in Parkinson's disease. Prog.Neuropsychopharmacol.Biol.Psychiatry, 28, 31-39.

Lezcano, E., Gomez, J. C., Lambarri, I., Bilbao, G., Pomposo, I., Rodriguez, O. et al. (2003). [Bilateral subthalamic nucleus deep-brain stimulation (STN-DBS) in Parkinson's disease: initial experience in Cruces Hospital]. Neurologia, 18, 187-195.

Liang, L., DeLong, M. R., \& Papa, S. M. (2008). Inversion of dopamine responses in striatal medium spiny neurons and involuntary movements. J.Neurosci., 28, 7537-7547.

Lilleeng, B., Gjerstad, M., Baardsen, R., Dalen, I., \& Larsen, J. P. (2015). The longterm development of non-motor problems after STN-DBS. Acta Neurol.Scand., 132, 251-258.

Liou, H. H., Tsai, M. C., Chen, C. J., Jeng, J. S., Chang, Y. C., Chen, S. Y. et al. (1997). Environmental risk factors and Parkinson's disease: a case-control study in Taiwan. Neurology, 48, 1583-1588.

Little, S. \& Bestmann, S. (2015). Computational neurostimulation for Parkinson's disease. Prog.Brain Res., 222, 163-190.

Little, S., Pogosyan, A., Neal, S., Zavala, B., Zrinzo, L., Hariz, M. et al. (2013). Adaptive deep brain stimulation in advanced Parkinson disease. Ann.Neurol., 74, 449-457.

Little, S., Pogosyan, A., Neal, S., Zrinzo, L., Hariz, M., Foltynie, T. et al. (2014). Controlling Parkinson's disease with adaptive deep brain stimulation. J.Vis.Exp..
Liu, T. W., Ma, Z. G., Zhou, Y., \& Xie, J. X. (2013). Transplantation of mouse CGR8 embryonic stem cells producing GDNF and $\mathrm{TH}$ protects against 6 -hydroxydopamine neurotoxicity in the rat. Int.J.Biochem.Cell Biol., 45, 1265-1273.

Lu, Y., Prudent, M., Fauvet, B., Lashuel, H. A., \& Girault, H. H. (2011). Phosphorylation of alpha-Synuclein at Y125 and S129 alters its metal binding properties: implications for understanding the role of alpha-Synuclein in the pathogenesis of Parkinson's Disease and related disorders. ACS Chem.Neurosci., 2, 667-675.

Luo, D., Shi, Y., Wang, J., Lin, Q., Sun, Y., Ye, K. et al. (2016). 7,8dihydroxyflavone protects 6-OHDA and MPTP induced dopaminergic neurons degeneration through activation of TrkB in rodents. Neurosci.Lett., 620, 43-49.

Madrazo, I., Drucker-Colin, R., Diaz, V., Martinez-Mata, J., Torres, C., \& Becerril, J. J. (1987). Open microsurgical autograft of adrenal medulla to the right caudate nucleus in two patients with intractable Parkinson's disease. N.Engl.J.Med., 316, 831-834.

Madrazo, I., Franco-Bourland, R., OstroskySolis, F., Aguilera Riestra, M. C., Madrazo, M., \& Zarate, A. (1989). [Autograft of the adrenal medulla to caudate nucleus as Parkinson disease treatment: long-term clinical evaluation]. Gac.Med.Mex., 125, 385-394.

Maggio, R., Riva, M., Vaglini, F., Fornai, F., Racagni, G., \& Corsini, G. U. (1997). Striatal increase of neurotrophic factors as a mechanism of nicotine protection in experimental parkinsonism. J.Neural Transm.(Vienna.), 104, 1113-1123.

Mahanthappa, N. K., Gage, F. H., \& Patterson, P. H. (1990). Adrenal chromaffin cells as multipotential neurons for autografts. Prog.Brain Res., 82, 33-39.

Manson, A., Stirpe, P., \& Schrag, A. (2012). Levodopa-induced-dyskinesias clinical features, incidence, risk factors, 
management and impact on quality of life. J.Parkinsons.Dis., 2, 189-198.

Marks, W. A., Honeycutt, J., Acosta, F., \& Reed, M. (2009). Deep brain stimulation for pediatric movement disorders. Semin.Pediatr.Neurol., 16, 90-98.

Martínez-Martínez, A., Aguilar, O., \& AcevedoTriana, C. (2016). Meta-analysis of the relationship between deep brain stimulation (DBS) in patients with Parkinson's disease and performance in evaluation tests for executive brain functions. Parkinsons.Dis., In press.

Masliah, E., Dumaop, W., Galasko, D., \& Desplats, P. (2013). Distinctive patterns of DNA methylation associated with Parkinson disease: identification of concordant epigenetic changes in brain and peripheral blood leukocytes. Epigenetics., 8, 1030-1038.

Mayeux, R. (2003). Epidemiology of neurodegeneration. Annu.Rev.Neurosci., 26, 81-104.

McCoy, M. K., Ruhn, K. A., Blesch, A., \& Tansey, M. G. (2011). TNF: a key neuroinflammatory mediator of neurotoxicity and neurodegeneration in models of Parkinson's disease. Adv.Exp.Med.Biol., 691, 539-540.

McGuire, V., Van Den Eeden, S. K., Tanner, C. M., Kamel, F., Umbach, D. M., Marder, K. et al. (2011). Association of DRD2 and DRD3 polymorphisms with Parkinson's disease in a multiethnic consortium. J.Neurol.Sci., 307, 22-29.

Mellick, G. D., Gartner, C. E., Silburn, P. A., \& Battistutta, D. (2006). Passive smoking and Parkinson disease. Neurology, 67, 179-180.

Meloni, G. \& Vasak, M. (2011). Redox activity of alpha-synuclein- $\mathrm{Cu}$ is silenced by $\mathrm{Zn}$ (7)metallothionein-3. Free Radic.Biol.Med., 50, 1471-1479.

Mercuri, N. B. \& Bernardi, G. (2005). The 'magic' of L-dopa: why is it the gold standard Parkinson's disease therapy? Trends Pharmacol.Sci., 26, 341-344.

Michel, A., Downey, P., Van, D., X, De, W. C., Schwarting, R., \& Scheller, D. (2015).
Behavioural Assessment of the A2a/NR2B Combination in the Unilateral 6-OHDALesioned Rat Model: A New Method to Examine the Therapeutic Potential of Non-Dopaminergic Drugs. PLoS.One., 10, e0135949.

Miksys, S. \& Tyndale, R. F. (2006). Nicotine induces brain CYP enzymes: relevance to Parkinson's disease. J.Neural Transm.Suppl, 177-180.

Mizuno, Y., Hattori, N., Kitada, T., Matsumine, H., Mori, H., Shimura, $H$. et al. (2001). Familial Parkinson's disease. Alphasynuclein and parkin. Adv.Neurol., 86, 13-21.

Mottonen, T., Katisko, J., Haapasalo, J., Tahtinen, T., Saastamoinen, A., Peltola, J. et al. (2016). The Correlation between Intraoperative Microelectrode Recording and 3-Tesla MRI in Patients Undergoing ANT-DBS for Refractory Epilepsy. Stereotact.Funct.Neurosurg., 94, 86-92.

Muller, M. L. \& Bohnen, N. I. (2013). Cholinergic dysfunction in Parkinson's disease. Curr.Neurol.Neurosci.Rep., 13, 377.

Munoz, A., Li, Q., Gardoni, F., Marcello, E., Qin, C., Carlsson, T. et al. (2008). Combined 5-HT1A and 5-HT1B receptor agonists for the treatment of L-DOPA-induced dyskinesia. Brain, 131, 3380-3394.

Murchison, A. G., Fletcher, C., \& Cheeran, B. (2016). Recurrence of dyskinesia as a side-effect of mirabegron in a patient with Parkinson's disease on DBS (GPi). Parkinsonism.Relat Disord., 27, 107-108.

Nagatsu, T., Mogi, M., Ichinose, H., \& Togari, A. (2000). Changes in cytokines and neurotrophins in Parkinson's disease. J.Neural Transm.Suppl, 277-290.

Nagatsu, T., Mogi, M., Ichinose, H., \& Togari, A. (2000). Cytokines in Parkinson's disease. J.Neural Transm.Suppl, 143-151.

Naoi, M., Maruyama, W., Niwa, T., \& Nagatsu, T. (1994). Novel toxins and Parkinson's disease: $\mathrm{N}$-methylation and oxidation as metabolic bioactivation of neurotoxin. J.Neural Transm.Suppl, 41, 197-205. 
Nowacki, A., Fiechter, M., Fichtner, J., Debove, I., Lachenmayer, L., Schupbach, M. et al. (2015). Using MDEFT MRI Sequences to Target the GPi in DBS Surgery. PLoS.One., 10, e0137868.

O'Keeffe, F. E., Scott, S. A., Tyers, P., O'Keeffe, G. W., Dalley, J. W., Zufferey, R. et al. (2008). Induction of A9 dopaminergic neurons from neural stem cells improves motor function in an animal model of Parkinson's disease. Brain, 131, 630-641.

O'Sullivan, D. \& Pell, M. (2009). Long-term follow-up of DBS of thalamus for tremor and STN for Parkinson's disease. Brain Res.Bull., 78, 119-121.

Obeso, J. A., Rodriguez-Oroz, M. C., Goetz, C. G., Marin, C., Kordower, J. H., Rodriguez, M. et al. (2010). Missing pieces in the Parkinson's disease puzzle. Nat.Med., 16, 653-661.

Okun, M. S. (2012). Deep-brain stimulation for Parkinson's disease. N.Engl.J.Med., 367, 1529-1538.

Okun, M. S. \& Foote, K. D. (2010). Parkinson's disease DBS: what, when, who and why? The time has come to tailor DBS targets. Expert.Rev.Neurother., 10, 1847-1857.

Okun, M. S., Wu, S. S., Fayad, S., Ward, H., Bowers, D., Rosado, C. et al. (2014). Acute and Chronic Mood and Apathy Outcomes from a randomized study of unilateral STN and GPi DBS. PLoS.One., 9, e114140.

Olson, L., Backlund, E. O., Ebendal, T., Freedman, R., Hamberger, B., Hansson, P. et al. (1991). Intraputaminal infusion of nerve growth factor to support adrenal medullary autografts in Parkinson's disease. One-year follow-up of first clinical trial. Arch.Neurol., 48, 373-381.

Ono, Y., Nakatani, T., Sakamoto, Y., Mizuhara, E., Minaki, Y., Kumai, M. et al. (2007). Differences in neurogenic potential in floor plate cells along an anteroposterior location: midbrain dopaminergic neurons originate from mesencephalic floor plate cells. Development, 134, 3213-3225.

Pacelli, C., Giguere, N., Bourque, M. J., Levesque, M., Slack, R. S., \& Trudeau,
L. E. (2015). Elevated Mitochondrial Bioenergetics and Axonal Arborization Size Are Key Contributors to the Vulnerability of Dopamine Neurons. Curr.Biol., 25, 2349-2360.

Pagano, G., Ferrara, N., Brooks, D. J., \& Pavese, N. (2016). Age at onset and Parkinson disease phenotype. Neurology, 86, 1400-1407.

Palacios, N., Gao, X., McCullough, M. L., Schwarzschild, M. A., Shah, R., Gapstur, S. et al. (2012). Caffeine and risk of Parkinson's disease in a large cohort of men and women. Mov Disord., 27, 1276-1282.

Perry, E. K., Perry, R. H., Smith, C. J., Dick, D. J., Candy, J. M., Edwardson, J. A. et al. (1987). Nicotinic receptor abnormalities in Alzheimer's and Parkinson's diseases. J.Neurol.Neurosurg.Psychiatry, 50, 806-809.

Prediger, R. D. (2010). Effects of caffeine in Parkinson's disease: from neuroprotection to the management of motor and nonmotor symptoms. J.Alzheimers.Dis., $20 \mathrm{Suppl}$ 1, S205-S220.

Priori, A., Foffani, G., Rossi, L., \& Marceglia, S. (2013). Adaptive deep brain stimulation (aDBS) controlled by local field potential oscillations. Exp.Neurol., 245, 77-86.

Quik, M. (2004). Smoking, nicotine and Parkinson's disease. Trends Neurosci., 27, 561-568.

Quik, M., Huang, L. Z., Parameswaran, N., Bordia, T., Campos, C., \& Perez, X. A. (2009). Multiple roles for nicotine in Parkinson's disease. Biochem.Pharmacol., 78, 677-685.

Quik, M., O'Neill, M., \& Perez, X. A. (2007). Nicotine neuroprotection against nigrostriatal damage: importance of the animal model. Trends Pharmacol.Sci., 28, 229-235.

Quik, M., Perez, X. A., \& Bordia, T. (2012). Nicotine as a potential neuroprotective agent for Parkinson's disease. Mov Disord., 27, 947-957.

Quik, M. \& Wonnacott, S. (2011). alpha6beta2* and alpha4beta2* nicotinic acetylcholine 
receptors as drug targets for Parkinson's disease. Pharmacol.Rev., 63, 938-966.

Quraan, M. A., Protzner, A. B., Daskalakis, Z. J., Giacobbe, P., Tang, C. W., Kennedy, S. H. et al. (2014). EEG power asymmetry and functional connectivity as a marker of treatment effectiveness in DBS surgery for depression. Neuropsychopharmacology, 39, 1270-1281.

Rahimmi, A., Khosrobakhsh, F., Izadpanah, E., Moloudi, M. R., \& Hassanzadeh, K. (2015). N-acetylcysteine prevents rotenone-induced Parkinson's disease in rat: An investigation into the interaction of parkin and Drp1 proteins. Brain Res.Bull., 113, 34-40.

Rezai, A. (2009). DBS for neurobehavioral disorders. Stereotact.Funct.Neurosurg., 87, 267.

Reznikoff, G., Manaker, S., Parsons, B., Rhodes, C. H., \& Rainbow, T. C. (1985). Similar distribution of monoamine oxidase (MAO) and parkinsonian toxin (MPTP) binding sites in human brain. Neurology, 35, 1415-1419.

Rinne, J. O., Myllykyla, T., Lonnberg, P., \& Marjamaki, P. (1991). A postmortem study of brain nicotinic receptors in Parkinson's and Alzheimer's disease. Brain Res., 547, 167-170.

Rodriguez-Oroz, M. C., Moro, E., \& Krack, P. (2012). Long-term outcomes of surgical therapies for Parkinson's disease. Mov Disord., 27, 1718-1728.

Rodriguez-Oroz, M. C., Obeso, J. A., Lang, A. E., Houeto, J. L., Pollak, P., Rehncrona, S. et al. (2005). Bilateral deep brain stimulation in Parkinson's disease: a multicentre study with 4 years follow-up. Brain, 128, 2240-2249.

Ross, G. W., Abbott, R. D., Petrovitch, H., Morens, D. M., Grandinetti, A., Tung, K. H. et al. (2000). Association of coffee and caffeine intake with the risk of Parkinson disease. JAMA, 283, 2674-2679.

Rubio-Osornio, M., Montes, S., Heras-Romero, Y., Guevara, J., Rubio, C., Aguilera, P. et al. (2013). Induction of ferroxidase enzymatic activity by copper reduces MPP+-evoked neurotoxicity in rats. Neurosci.Res., 75, 250-255.

Sakas, D. E., Kouyialis, A. T., Boviatsis, E. J., Panourias, I. G., Stathis, P., \& Tagaris, G. (2007). Technical aspects and considerations of deep brain stimulation surgery for movement disorders. Acta Neurochir.Suppl, 97, 163-170.

Sampson, T. R., Debelius, J. W., Thron, T., Janssen, S., Shastri, G. G., Ilhan, Z. E. et al. (2016). Gut Microbiota Regulate Motor Deficits and Neuroinflammation in a Model of Parkinson's Disease. Cell, 167, 1469-1480.

Sawle, G. V., Bloomfield, P. M., Bjorklund, A., Brooks, D. J., Brundin, P., Leenders, K. L. et al. (1992). Transplantation of fetal dopamine neurons in Parkinson's disease: PET [18F]6-L-fluorodopa studies in two patients with putaminal implants. Ann.Neurol., 31, 166-173.

Schapira, A. H. (2013). Recent developments in biomarkers in Parkinson disease. Curr.Opin.Neurol., 26, 395-400.

Schober, A. (2004). Classic toxin-induced animal models of Parkinson's disease: 6-OHDA and MPTP. Cell Tissue Res., 318, 215-224.

Schwarzschild, M. A., Chen, J. F., \& Ascherio, A. (2002). Caffeinated clues and the promise of adenosine $\mathrm{A}(2 \mathrm{~A})$ antagonists in PD. Neurology, 58, 1154-1160.

Semchuk, K. M., Love, E. J., \& Lee, R. G. (1991). Parkinson's disease and exposure to rural environmental factors: a population based case-control study. Can.J.Neurol.Sci., 18, 279-286.

Sershen, H., Hashim, A., \& Lajtha, A. (1987). Behavioral and biochemical effects of nicotine in an MPTP-induced mouse model of Parkinson's disease. Pharmacol.Biochem.Behav., 28, 299-303.

Sherer, T. B., Betarbet, R., Stout, A. K., Lund, S., Baptista, M., Panov, A. V. et al. (2002). An in vitro model of Parkinson's disease: linking mitochondrial impairment to altered alpha-synuclein metabolism 
and oxidative damage. J.Neurosci., 22, 7006-7015.

Shimoke, K. \& Chiba, H. (2001). Nerve growth factor prevents 1-methyl-4-phenyl-1,2,3,6tetrahydropyridine-induced cell death via the Akt pathway by suppressing caspase-3like activity using PC12 cells: relevance to therapeutical application for Parkinson's disease. J.Neurosci.Res., 63, 402-409.

Shoulson, I., Oakes, D., Fahn, S., Lang, A., Langston, J. W., LeWitt, P. et al. (2002). Impact of sustained deprenyl (selegiline) in levodopa-treated Parkinson's disease: a randomized placebo-controlled extension of the deprenyl and tocopherol antioxidative therapy of parkinsonism trial. Ann.Neurol., 51, 604-612.

Singer, T. P., Castagnoli, N., Jr., Ramsay, R. R., \& Trevor, A. J. (1987). Biochemical events in the development of parkinsonism induced by 1-methyl-4-phenyl-1,2,3,6tetrahydropyridine. J.Neurochem., 49, 1-8.

Singer, T. P. \& Ramsay, R. R. (1990). Mechanism of the neurotoxicity of MPTP. An update. FEBS Lett., 274, 1-8.

Soto-Otero, R., Mendez-Alvarez, E., SanchezSellero, I., Cruz-Landeira, A., \& LopezRivadulla, L. M. (2001). Reduction of rat brain levels of the endogenous dopaminergic proneurotoxins 1,2,3,4-tetrahydroisoquinoline and 1,2,3,4tetrahydro-beta-carboline by cigarette smoke. Neurosci.Lett., 298, 187-190.

Stefani, A., Fedele, E., Vitek, J., Pierantozzi, M., Galati, S., Marzetti, F. et al. (2011). The clinical efficacy of L-DOPA and STNDBS share a common marker: reduced GABA content in the motor thalamus. Cell Death.Dis., 2, e154.

Stegemoller, E. L., Vallabhajosula, S., Haq, I., Hwynn, N., Hass, C. J., \& Okun, M. S. (2013). Selective use of low frequency stimulation in Parkinson's disease based on absence of tremor. NeuroRehabilitation., 33, 305-312.

Su, F., Wang, J., Deng, B., Wei, X. L., Chen, Y. Y., Liu, C. et al. (2015). Adaptive control of Parkinson's state based on a nonlinear computational model with unknown parameters. Int.J.Neural Syst., 25, 1450030.

Tanner, C. M. (1989). The role of environmental toxins in the etiology of Parkinson's disease. Trends Neurosci., 12, 49-54.

Thiriez, C., Villafane, G., Grapin, F., Fenelon, G., Remy, P., \& Cesaro, P. (2011). Can nicotine be used medicinally in Parkinson's disease? Expert.Rev.Clin.Pharmacol., 4, 429-436.

Tong, Q., Wu, L., Jiang, T., Ou, Z., Zhang, Y., \& Zhu, D. (2016). Inhibition of endoplasmic reticulum stress-activated IRE1alphaTRAF2-caspase-12 apoptotic pathway is involved in the neuroprotective effects of telmisartan in the rotenone rat model of Parkinson's disease. Eur.J.Pharmacol., 776, 106-115.

Udupa, K. \& Chen, R. (2015). The mechanisms of action of deep brain stimulation and ideas for the future development. Prog.Neurobiol., 133, 27-49.

Vallabhajosula, S., Haq, I. U., Hwynn, N., Oyama, G., Okun, M., Tillman, M. D. et al. (2015). Low-frequency versus highfrequency subthalamic nucleus deep brain stimulation on postural control and gait in Parkinson's disease: a quantitative study. Brain Stimul., 8, 64-75.

Van, N. B., Raedt, R., Delbeke, J., Wadman, W. J., Boon, P., \& Vonck, K. (2015). In search of optimal DBS paradigms to treat epilepsy: bilateral versus unilateral hippocampal stimulation in a rat model for temporal lobe epilepsy. Brain Stimul., 8, 192-199.

Varani, K., Vincenzi, F., Tosi, A., Gessi, S., Casetta, I., Granieri, G. et al. (2010). A2A adenosine receptor overexpression and functionality, as well as TNF-alpha levels, correlate with motor symptoms in Parkinson's disease. FASEB J., 24, 587-598.

Vieregge, A., Sieberer, M., Jacobs, H., Hagenah, J. M., \& Vieregge, P. (2001). Transdermal nicotine in PD: a randomized, doubleblind, placebo-controlled study. Neurology, 57, 1032-1035. 
Villafane, G., Cesaro, P., Rialland, A., Baloul, S., Azimi, S., Bourdet, C. et al. (2007). Chronic high dose transdermal nicotine in Parkinson's disease: an open trial. Eur.J.Neurol., 14, 1313-1316.

Visser-Vandewalle, V., Temel, Y., van der Linden, C., Ackermans, L., \& Beuls, E. (2004). Deep brain stimulation in movement disorders. The applications reconsidered. Acta Neurol.Belg., 104, 33-36.

Wakeman, D. R., Redmond, D. E., Jr., Dodiya, H. B., Sladek, J. R., Jr., Leranth, C., Teng, Y. D. et al. (2014). Human neural stem cells survive long term in the midbrain of dopamine-depleted monkeys after GDNF overexpression and project neurites toward an appropriate target. Stem Cells Transl.Med., 3, 692-701.

Wang, Y., Lee, J. W., Oh, G., Grady, S. R., McIntosh, J. M., Brunzell, D. H. et al. (2014). Enhanced synthesis and release of dopamine in transgenic mice with gain-offunction alpha6* nAChRs. J.Neurochem., 129, 315-327.

Waxman, E. A. \& Giasson, B. I. (2011). Induction of intracellular tau aggregation is promoted by alpha-synuclein seeds and provides novel insights into the hyperphosphorylation of tau. J.Neurosci., 31, 7604-7618.

Wenker, S. D., Casalia, M., Candedo, V. C., Casabona, J. C., \& Pitossi, F. J. (2015). Cell reprogramming and neuronal differentiation applied to neurodegenerative diseases: Focus on Parkinson's disease. FEBS Lett., 589, 3396-3406.

Whetten-Goldstein, K., Sloan, F., Kulas, E., Cutson, T., \& Schenkman, M. (1997). The burden of Parkinson's disease on society, family, and the individual. J.Am.Geriatr.Soc., 45, 844-849.

Widner, H., Tetrud, J., Rehncrona, S., Snow, B., Brundin, P., Gustavii, B. et al. (1992). Bilateral fetal mesencephalic grafting in two patients with parkinsonism induced by 1-methyl-4-phenyl-1,2,3,6- tetrahydropyridine (MPTP). N.Engl.J.Med., 327, 1556-1563.

Williams, N. R., Hopkins, T. R., Short, E. B., Sahlem, G. L., Snipes, J., Revuelta, G. J. et al. (2016). Reward circuit DBS improves Parkinson's gait along with severe depression and OCD. Neurocase., 22, 201-204.

Willis, A. W. (2013). Parkinson disease in the elderly adult. Mo.Med., 110, 406-410.

Willis, A. W., Evanoff, B. A., Lian, M., Galarza, A., Wegrzyn, A., Schootman, M. et al. (2010). Metal emissions and urban incident Parkinson disease: a community health study of Medicare beneficiaries by using geographic information systems. Am.J.Epidemiol., 172, 1357-1363.

Willis, A. W., Evanoff, B. A., Lian, M., Galarza, A., Wegrzyn, A., Schootman, M. et al. (2010). Metal emissions and urban incident Parkinson disease: a community health study of Medicare beneficiaries by using geographic information systems. Am.J.Epidemiol., 172, 1357-1363.

Xu, K., Xu, Y. H., Chen, J. F., \& Schwarzschild, M. A. (2010). Neuroprotection by caffeine: time course and role of its metabolites in the MPTP model of Parkinson's disease. Neuroscience, 167, 475-481.

Yang, A. I., Vanegas, N., Lungu, C., \& Zaghloul, K. A. (2014). Beta-coupled high-frequency activity and beta-locked neuronal spiking in the subthalamic nucleus of Parkinson's disease. J.Neurosci., 34, 12816-12827.

Yin, G., Lopes da, F. T., Eisbach, S. E., Anduaga, A. M., Breda, C., Orcellet, M. L. et al. (2014). alpha-Synuclein interacts with the switch region of Rab8a in a Ser129 phosphorylation-dependent manner. Neurobiol.Dis., 70, 149-161.

Yokel, R. A. (2006). Blood-brain barrier flux of aluminum, manganese, iron and other metals suspected to contribute to metal-induced neurodegeneration. J.Alzheimers.Dis., 10, 223-253.

Zhang, Z., Cui, W., Li, G., Yuan, S., Xu, D., Hoi, M. P. et al. (2012). Baicalein protects against 6-OHDA-induced neurotoxicity 
through activation of Keap1/Nrf2/HO-1 and involving PKCalpha and PI3K/AKT signaling pathways. J.Agric.Food Chem., 60, 8171-8182.

Zhou, W., Bercury, K., Cummiskey, J., Luong, N., Lebin, J., \& Freed, C. R. (2011). Phenylbutyrate up-regulates the DJ-1 protein and protects neurons in cell culture and in animal models of Parkinson disease. J.Biol.Chem., 286, 14941-14951.

Zhou, Y., Zhang, Y., Li, J., Lv, F., Zhao, Y., Duan, D. et al. (2012). A comprehensive study on long-term injury to nigral dopaminergic neurons following intracerebroventricular injection of lipopolysaccharide in rats. J.Neurochem., 123, 771-780.

Zhu, B., Caldwell, M., \& Song, B. (2016). Development of stem cell-based therapies for Parkinson's disease. Int.J.Neurosci., 126, 955-962.

\section{Notas}

* Artículo de investigación. 